\title{
THE RELATIVE DEPRIVATION TRAP: HOW FEELING DEPRIVED RELATES TO SYMPTOMS OF GENERALIZED ANXIETY DISORDER
}

\author{
by (C) Jonah Samuel Nadler \\ A thesis submitted to the School of Graduate Studies \\ in partial fulfillment of the requirements for the degree of

\section{Doctor of Psychology} \\ Department of Psychology, Faculty of Science \\ Memorial University of Newfoundland
}

February 2021

St. John's, Newfoundland and Labrador 


\begin{abstract}
The psychological factors that explain how income inequality is associated with poorer mental health remain unclear. Personal relative deprivation (PRD), defined as the subjective distress experienced as a result of appraising oneself as unfairly disadvantaged compared to similar others, has been associated with poorer mental health, and may help explain this association. Generalized anxiety disorder (GAD) is a highly prevalent psychological disorder associated with negative cognitive appraisals. Accordingly, PRD may relate to the experience of GAD and to cognitive processes associated with GAD. In two studies we tested whether PRD was associated with GAD symptoms and if this relationship could be explained by cognitive predictors of GAD including Intolerance of Uncertainty (IU), Positive Beliefs about Worry (PBW), Negative Beliefs about Worry (NBW), and Experiential Avoidance (EA). Participants completed surveys measuring their experiences of PRD, cognitive predictors of GAD, GAD symptomology, subjective socioeconomic status, self-efficacy, and self-esteem. We found a consistent relationship between PRD and GAD. IU and NBW simultaneously mediated this relationship, while PBW and EA did not. These results remained when statistically adjusting for subjective socioeconomic status but were weakened when statistically adjusting for self-concept factors. This research suggests that the experience of relative deprivation may "trap" people in thinking patterns that contribute to symptoms of anxiety.
\end{abstract}




\section{General Summary}

People often interact with, notice, and think about others similar to them. When doing so, they will almost inevitably make comparisons. These comparisons, particularly when they are to those in a more favourable life circumstance, can lead to people feeling that they are relatively deprived; that they haven't received what they deserve. Being in societies in which people have more unequal incomes and status can exacerbate this experience, as the differences between individuals are intensified. This experience of deprivation, which involves feelings of anger or resentment, may be linked to poorer mental health outcomes. Accordingly, this research examined whether feelings of deprivation were related to symptoms of generalized anxiety disorder (GAD). GAD is typified by chronic and distressing worries, or repeating "what if" questions about potential future negative events. This research also tested whether the thinking patterns that are related to GAD may help to explain the relationship between feeling deprived and GAD symptoms. Such thinking patterns include people's beliefs about whether their worries are harmful or helpful, their comfort with uncertainty, and their desire to avoid emotions. Across two studies we found consistent evidence in community samples that feeling relatively deprived is related to experiencing symptoms of GAD. In addition, we found that believing that your worry is dangerous, as well as being uncomfortable with uncertain situations likely helped to explain the relationship between feeling deprived and symptoms of anxiety. These relationships were maintained when participants' age and socioeconomic status were taken into account, but became weaker (but still significant) when taking into account participants' self-esteem and other related feelings about themselves. Overall, this research suggests that feeling relatively deprived may "trap" people into thinking patterns that contribute to symptoms of anxiety. 


\section{Acknowledgements}

There's something so exciting and humbling that in my attempt to bring together social and clinical psychology - really my attempt to understand how those around us can shape who we are - that I have so much gratitude to share with those around me. So, thank you all for just being with me as I went from being a very confused and equally insecure boy, to a slightly less confused but certainly more confident and self-accepting old-man-child.

Marty you have provided unwavering support and belief in me throughout this project. Your keen eye for detail, guidance, and patience have helped me grow far beyond what I expected. I am deeply grateful for your calm demeanour and unique perspectives that helped to both keep me grounded and moving forward. Many thanks to Dr. Sandeep Mishra and Dr. Shadi Beshai for so generously sharing your research to facilitate the development of this project, and for your time and insight while writing this thesis and associated manuscripts.

To all my supervisors, thank you for being so giving with your time and knowledge, and for holding space for my growth. It is truly incredible to be able draw on all your wisdom every day. To the friends of Tiffany, thank you for endless support with all my learning, and more importantly for being there for all the times outside of learning. To Cally, Emily, Megan, Nicole, and Vanessa, I will never forget all you have done for me. Thank you for your sharing your passion and vulnerability, your brilliance and insights, your fun and your love.

To the Hustle \& Co. and the Squad, you were all so amazing in helping me squeeze every bit of joy out of the past 9 years of my life (and I know you'll continue to do that for years to come). Turning to you for laughs, friendship, and unconditional acceptance during my highs and my lows has made this journey so much richer.

Alfie, Archie, and Loki, you are all very good boys. You are good boys, yes you are. 
Kim and Charlie, thank you for giving me a home (and plenty of food) on an island in the middle of an ocean.

To my Bubbies and Zaidies - Helen and Jerrick, Sukie and Marty - thank you for loving me whole-heartedly and helping me bring that whole-heartedness to everything that I do.

Mom and Dad, Michelle and Rebecca, it's difficult to find the words that really capture what you mean to me, but as always when serious prose fails, a pun prevails. You have been the best parents and THESISters a son and younger brother could ask for. You have shown me what it means to truly care for others and have helped me foster the passion to make it my career. I feel immeasurably blessed to be able to turn to you in my darkest moments, greatest accomplishments, and everything in between knowing that I will always be met with humour and heart, and with love and logistics.

To Sydney, thank you for helping me learn to believe and trust in myself. You've allowed me to bring the best of myself to all aspects of my life and shown me it is really all about balance. You are my SBF. 


\section{Table of Contents}

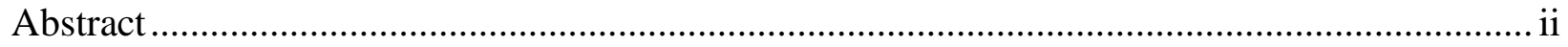

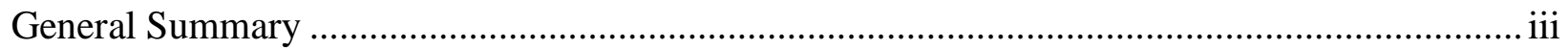

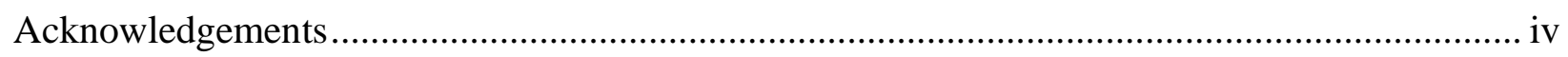

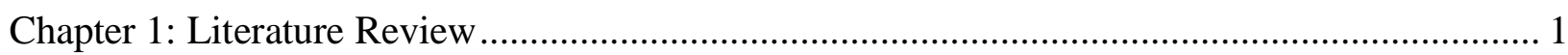

1.1 The Relationship Between Inequality and Mental Health ................................................... 1

1.2 Personal Relative Deprivation (PRD) Theory \& History ...................................................... 2

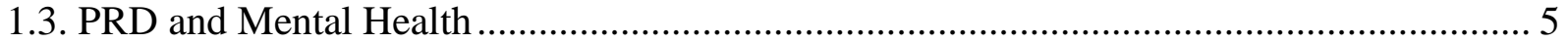

1.4 Generalized Anxiety Disorder (GAD) ……………................................................... 7

1.5 Cognitive Procceses Related to GAD ………………................................................... 9

1.6 Links Between PRD and Cognitive Processes of GAD .................................................. 10

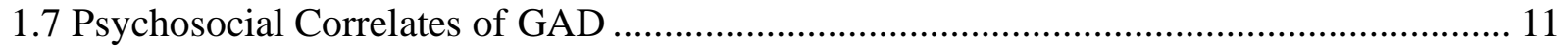

1.8 Present Research ..................................................................................................... 12

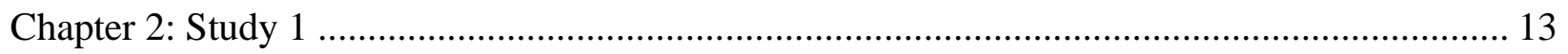

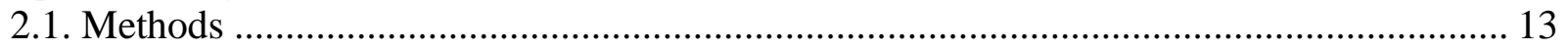

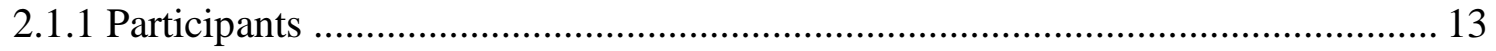

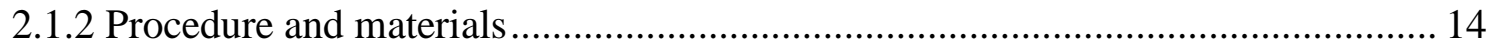

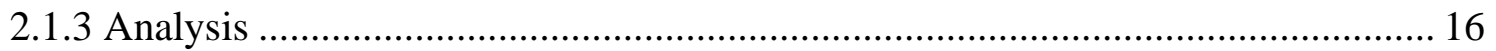

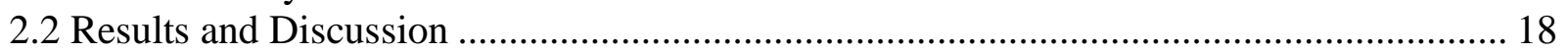

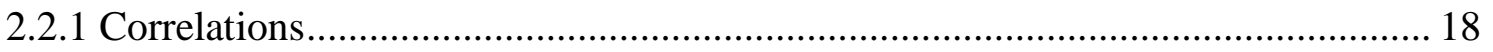

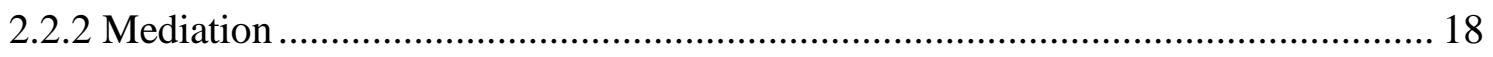

2.2.3 Study 1 Discussion .......................................................................................... 20

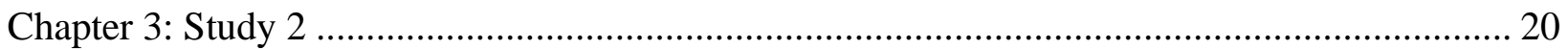

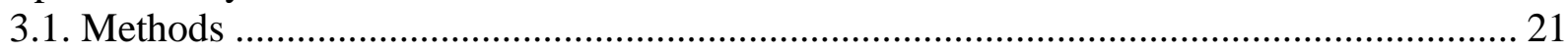

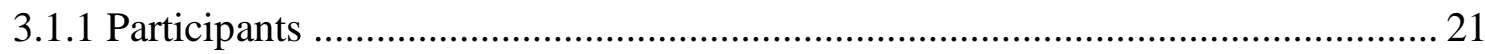

3.1.2 Procedure and materials ............................................................................ 22

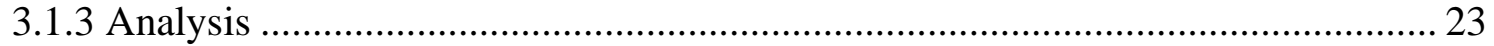

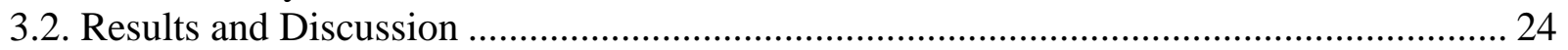

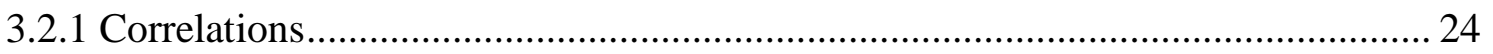

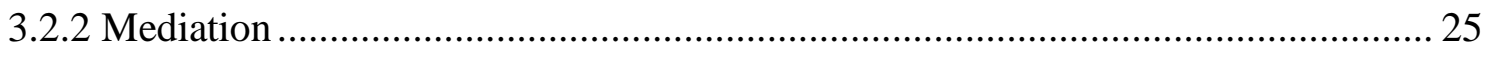

3.2.3 Study 2 Discussion ........................................................................................ 27

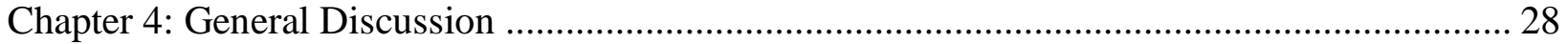

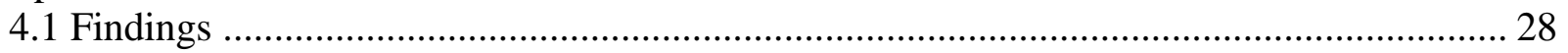

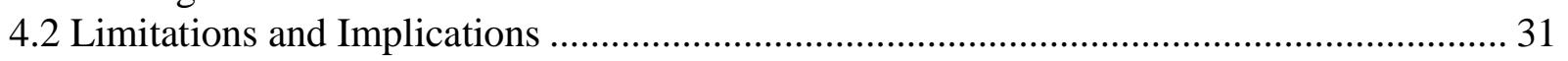

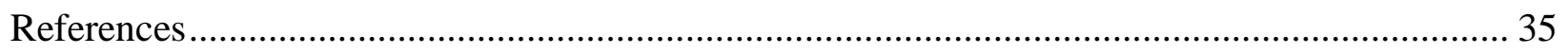

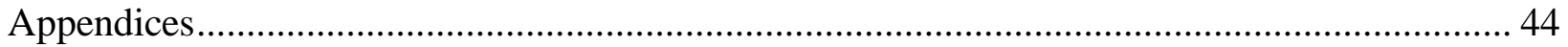

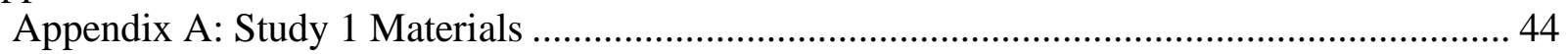

Appendix B: Study 1 Assumption Checks …………………………………………….... 47

Appendix C: Study 1 Additional Analysis and Model ........................................................... 48

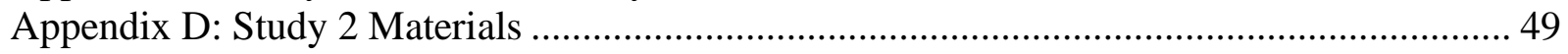

Appendix E: Study 1 Assumption Checks ...................................................................... 52

Appendix F: Study 2 Additional Analyses and Models ....................................................... 53 


\section{Chapter 1: Literature Review}

\subsection{The Relationship Between Inequality and Mental Health}

Differences in mental health and well-being are particularly striking in countries characterized by high inequality (Buttrick \& Oishi, 2017; Pickett \& Wilkinson, 2015; Wilkinson $\&$ Pickett, 2006). For example, the size of the gap between the rich and poor, as measured by the Gini coefficient or other ratios of the low to high income earners, is associated with societal rates of anxiety, impulse control disorders, depression, and addictions (Filho et al., 2013; Kessler et al., 2009; Pickett et al., 2006; Pickett \& Wilkinson, 2010; Weich et al., 2001). While the strength of these associations vary, one study found that individuals living in areas of high inequality, relative to areas of low inequality, were 1.53 times more likely to experience depression (Filho et al., 2013), while another found that the ratio of the top $20 \%$ to bottom $20 \%$ of incomes correlated $r=0.73$ with prevalence of current mental illness (Pickett et al., 2006). It has also been argued that there is a particularly strong positive association between inequality and anxiety disorders as a group (Wilkinson \& Pickett, 2010), and this relationship is not fully explained by people's objective socioeconomic status (SES; Kondo et al., 2009; Pickett et al., 2006).

Emerging research suggests that people's psychological reactions to inequality - such as lower levels of social trust and greater tendency to feel inferior to others - may in part explain the relationship between inequality and overall mental health (Cheung \& Lucas, 2016; Delhey \& Dragolov, 2014). In addition, inequality may be partially linked to increased symptomology and diagnosis of psychological disorders through lower perceived SES (one's subjective appraisal of where they fall in the social hierarchy), less trust in others, and less social cohesion (Ehsan \& De Silva, 2015; Scott et al., 2014). Crucially, this relationship between perceived SES and poor mental health exists even when accounting for peoples' objective SES, highlighting the 
importance of people's perceptions of their status in determining mental health outcomes (Scott et al., 2014).

\subsection{Personal Relative Deprivation (PRD) Theory \& History}

Another psychological process that may help to understand the link between inequality and psychological disorders is personal relative deprivation (PRD). PRD occurs when people compare themselves to similar others, appraise themselves to be at an unfair disadvantage, and react with dissatisfaction, anger and resentment (Smith \& Huo, 2014). PRD theory attempts to explain how people react both psychologically and behaviourally to deprivation, or the feeling associated with the belief that they are not receiving a deserved outcome (Crosby, 1976; Walker \& Pettigrew, 1984). Preliminary research suggests that living in areas of greater inequality as measured by the Gini coefficient (e.g., at the state or neighbourhood level) is related to greater individual experience of PRD (Hastings, 2019; Osborne et al., 2015). Given this potential relationship, PRD may form a "bridge" between the objective realities of inequality, and increased rates of mental illness (Hastings, 2019; Pettigrew, 2016; Walker \& Smith, 2002). Because it has been argued that anxiety disorders have been associated with inequality (Pickett \& Wilkinson, 2010), we consider whether PRD, inasmuch as it indexes reactions to inequality, may have a role in this relationship.

For decades, PRD has been used to explain people's reactions to objective circumstances by emphasizing the role their subjective comparisons play in determining their responses. In his American Solider studies, Samuel Stouffer (1949) first devised PRD as a post-hoc explanation for the paradoxical finding that military police were more content with their slow promotions than members of the air corps were with their rapid promotions. Stouffer argued that the policemen's immediate comparisons to the more salient referent, other police officers, made 
them feel more satisfied with their current position, in contrast to members of the air corps whose immediate referent group were being quickly promoted (Pettigrew, 2015). In these studies, Stouffer assumed that people's reactions to objective circumstances were largely determined by the subjective comparisons they made. However, he did not measure subjective experiences of deprivation. Consequently, while this early research offered a valuable perspective, the lack of operational definition and empirical support for PRD caused confusion in the literature, with numerous and sometimes conflicting conceptualizations of PRD emerging (Pettigrew, 2016). In the years following Stouffer's original studies, PRD theory has been further developed and refined to address confusion and criticisms of the concept. In the following section, we present the current understanding and definition of PRD theory, and differentiate between personal and group deprivation, as well as between relative and objective deprivation. (Crosby, 1982; Osborne et al., 2012; Stouffer et al., 1949).

Current PRD theory contends that a series of cognitive and affective factors relate societal inequality to individual-level outcomes (Bernstein \& Crosby, 1980; Smith \& Huo, 2014). First, one's position in society (e.g., based on income or employment status) can motivate people to make comparisons on personally relevant dimensions of success (e.g., income, job title, speed of promotion) to those around them, or even to different versions of themselves (Smith et al., 2012; Smith \& Huo, 2014). In reaction, some people may believe that they are at a disadvantage. Critically, PRD involves the subjective experience of being at an unfair disadvantage compared to similar others, and the immediate emotions (anger, resentment) resulting from this process (Crosby, 1976; Smith \& Pettigrew, 2015). As a consequence, PRD can be experienced throughout the social hierarchy, although it tends to be modestly stronger among those lower in SES (Callan et al., 2015a). 
Deprivation can be experienced at the individual or group level. The distinction between personal relative deprivation and group relative deprivation (GRD) was first articulated by Runciman (e.g., Runciman \& Runciman,1966). He argued that while PRD involves a person comparing their own situation to other people's situations, GRD involves people comparing the objective circumstances of their in-group to those of an out-group, and experiencing deprivation on behalf of their in-group (Pettigrew, 2016). This distinction has helped theorists more accurately predict and test relationship between deprivation and its correlates. Specifically, PRD appears to be more closely associated with personal outcomes (e.g., internal feelings, individual physical and mental health; see Mishra \& Carleton, 2015; Smith et al., 2020), while GRD is associated with group reactions and collective responses (e.g., protests, voting behaviours; see Smith \& Ortiz, 2002; Tougas \& Beaton, 2002). In short, when the level of analysis of deprivation and variables match, deprivation shows a somewhat stronger relationship with a variety of outcomes, relative to when they do not match (Smith et al., 2012). In a meta-analysis by Smith et al. (2012), the overall strength of the relationship between deprivation and outcomes for matched studies was $r=.166$, while the same relationship for mismatched studies was $r=$ $.113(p<.05)$. For studies of higher quality (i.e., with multi-item validated measures of deprivation, including its affective components), the gap in effect size appears to be larger, with a relationship between deprivation and individual or collective behaviour of $r=.253$ for matched studies, versus $r=.099$ for mismatched studies, though this difference only approached significance $(p<.08$; Smith et al., 2012).

A further distinction made following Stouffer's early research was between subjective measures of deprivation (i.e., PRD) and objective measures of deprivation. These latter "absolute" conceptualizations of deprivation are often defined as the difference between a 
person's income and that of all those with greater incomes within their reference group (AdjayeGbewonyo \& Kawachi, 2012). As the objective measures of deprivation assume the type and target of the comparisons, and are calculated from aggregate, macro-level data, they may not accurately capture people's experience of deprivation. For example, someone who experiences high objective deprivation (e.g., possessing low SES in a society of high economic disparity), but does not perceive it as unfair or problematic, should not experience PRD (Walker \& Pettigrew, 1984). Similarly, someone who expereinces low objective deprivation (e.g., possessing high SES in a society of high economic disparity) may still experience PRD if they make comparisons to their immediate comparators with even greater wealth. While objective measures of deprivation partly explain some individual based outcomes, subjective experiences of deprivation tend to have greater association with individual outcomes and behaviours (Smith et al., 2012).

Finally, a number of factors have been associated with the experience of PRD. For example, having greater individualistic beliefs (i.e., valuing individual achievement and autonomy) relates to greater experience of PRD, as does being of younger age (Callan, Kim, \& Matthews, 2015a; Smith et al., 2018). Specifically, even when controlling for indexes of objective socioeconomic status, PRD is weakest among older adults (aged 60 or greater), as this group typically engages in less social comparison, and thus experiences less PRD (Callan, Kim, et al., 2015a).

\subsection{PRD and Mental Health}

The experience of PRD is associated with poor outcomes on broad measures of mental health and well-being. For example, greater PRD has been associated with higher levels of affective and anxiety concerns among a Canadian community sample, controlling for a number of demographic variables such as level of education, employment status, household income, and 
social support (Mishra \& Carleton, 2015). Similarly, Callan, Kim, et al (2015b) produced a number of studies highlighting PRD's relationship with negative affect, self-rated symptoms of depression, and perceived stress. They found that higher levels of PRD among online survey participants were related with greater negative affect (as measured by the negative affect subscale of the PANAS) and self-reported depression symptoms (as measured by the CES-D), while controlling for income and level of education (Callan, Kim, et al., 2015b). Additionally, among similar samples they found that PRD predicted perceived stress, while controlling for subjective socioeconomic status, income and education. Moreover, these studies showed that changes in PRD were a better predictor of perceived stress than subjective socioeconomic status over a 6-week period. Smith et al. (2020), have further reported that in a longitudinal study of 168 students at a state university, greater experience of PRD predicted poorer self-reported mental health two years later. Greater feelings of deprivation have also been associated with greater trait aggression, as well as greater feelings of interpersonal hostility (Greitemeyer \& Sagioglou, 2016, 2017). Moreover, experiencing deprivation is associated with greater impulsivity, risk prone attitudes, gambling, and antisocial behaviour (Callan, Will Shead, et al., 2015; Mishra \& Meadows, 2018; Mishra \& Novakowski, 2016).

In the domain of psychopathology, PRD has been positively associated with greater selfreported lifetime history of diagnosed mental-illness, depressive symptomology, as well as broad cognitive and affective indicators of mood and anxiety disorders (Beshai, Mishra, Meadows, et al., 2017; Callan, Kim, et al., 2015b; Mishra \& Carleton, 2015). More specifically, among online community samples, PRD has been associated with several emotional and cognitive processes associated with the onset and maintenance of depression, including negative automatic thoughts about the self, dysfunctional attitudes, and a tendency to suppress emotions (Beshai, Mishra, 
Meadows, et al., 2017). In particular, the relationship between PRD and depressive symptomology in primarily healthy community samples appears to be primarily mediated by negative automatic thoughts about the self (Beshai, Mishra, Meadows, et al., 2017).

Although associations have been established between PRD and mental well-being and depression, as well as some cognitive factors implicated in psychopathology, it is unknown if PRD is associated with anxiety pathology specifically, and if so, which cognitive mechanisms link the two. Given the relation between PRD and the cognitive processes associated with depression, it is possible that PRD may also relate to cognitive processes associated with specific anxiety disorders.

\subsection{Generalized Anxiety Disorder (GAD)}

Generalized anxiety disorder (GAD) is the most common of anxiety disorders, has a number of cognitive predictors that may be related to PRD, and thus represents a promising target of investigation in the context of PRD (Kroenke et al., 2007). However, to our knowledge, no empirical research has examined whether the tendency to experience PRD can, in part, explain the degree to which people experience symptoms of anxiety disorders, including those of generalized anxiety. In the following, we review (a) the core features and impact of GAD, (b) cognitive processes related to GAD specifically, (c) how these cognitive processes may link PRD to GAD, and (d) other important psychosocial correlates of GAD. We then present two empirical studies examining associations of PRD and generalized anxiety, as well as cognitive mediators that may link the two.

GAD is typified by chronic, excessive, and uncontrollable worry that pervades a person's life. The worry experienced in GAD takes the form of repetitive thinking (e.g., recursive "whatif” questions) about potential threats and risks (E. R. Watkins, 2008). As a result of this worry, 
people who experience GAD also experience physical and behavioural manifestations of anxiety (e.g., fatigue, muscle tension, sleep disturbances; American Psychological Association, 2013). The worry experienced in GAD is different than nonpathological worry because it is experienced in response to a wider range of perceived stressors, is greater in intensity, frequency, and duration, and interferes with people's ability to function in their daily lives (American Psychological Association, 2013; Valentiner et al., 2014).

The lifetime prevalence of GAD is estimated at $3.7 \%$ worldwide, $5.7 \%$ in the U.S., and 8.7\% in Canada, though differences in prevalence may be accounted for by differences in measurement tools or study design (e.g., use of diagnostic interviews versus rating scales; Pearson et al., 2013; Ruscio et al., 2017; Valentiner et al., 2014; Watterson et al., 2017). While GAD can be experienced across the lifespan, the onset of GAD is most often in young adulthood to middle age, with $75 \%$ of cases emerging before 53-years-old (Ruscio et al., 2017). GAD is a chronic disorder, with over $50 \%$ of cases lasting longer than 12 months (Ruscio et al., 2017). The disorder impacts numerous areas of functioning, and is associated with reduced quality of life in overall health, role functioning, and social functioning (Kessler et al., 2005; Wittchen, 2002). Even people who do not meet full diagnostic criteria and present with sub-threshold levels of GAD experience some of these impairments (Haller et al., 2014). In fact, severe role impairment from GAD is highest in high-income countries, relative to middle-income and low-income nations, but disproportionately impacts those of lower socioeconomic status within countries (Ruscio et al., 2017). While the reasons for these inverse relationships at the national and individual level are not entirely clear, some argue that it is because there are greater expectations on individuals in high-income western countries to independently succeed in a number of domains (e.g., occupation, status), despite individuals in these areas typically having less 
community support to maintain their well-being relative to middle- or low-income countries (Dückers et al., 2016; Luthar, 2003; Ruscio et al., 2017).

\subsection{Cognitive Procceses Related to GAD}

A number of theories have been developed to understand the psychological mechanisms that contribute to the development and maintenance of GAD. Many of these theories share an underlying assumption that the worry seen in GAD can be conceptualized as a cognitive coping response to subjectively distressing experiences (Valentiner et al., 2014). The intolerance of uncertainty $(I U)$ model argues that people with greater IU react negatively on cognitive, emotional, and behavioural levels to uncertain situations or events (Dugas et al., 2004). People who experience greater IU find the possibility of a negative future event transpiring to be unacceptable regardless of the likelihood of its occurrence (Buhr \& Dugas, 2006; Norr et al., 2013). They tend to engage in worry as a maladaptive means of gaining greater certainty about future situations, and to resolve their distress (Koerner \& Dugas, 2006). This worry has, in turn, been associated with greater experience of GAD (Boswell et al., 2014; Dugas et al., 2004).

The metacognitive model of GAD argues that both people's positive and negative beliefs about worry can contribute to greater experience of GAD. This theory suggests that people see worry as a cognitive coping response that can help to problem-solve and resolve anticipated threats (Gentes \& Ruscio, 2011; Ruscio \& Borkovec, 2004; E. R. Watkins, 2008). People who hold these positive beliefs about the utility of worry $(P B W)$ view worrying as an effective means of coping with difficulties, potentially increasing their vulnerability to GAD (Ruscio \& Borkovec, 2004). This worry can be positively reinforced in the short term as it allows people to soothe their anxiety as they develop a belief in their ability to cope through worry (Wells, 2004). As people engage in greater levels of worry, they can simultaneously develop and hold negative 
appraisals of their worries - that their worrying is uncontrollable, dangerous, or that they are unable to cope with it (E. Watkins, 2004; Wells, 2005). These negative beliefs about worry $(N B W)$ can contribute to strategies that are ineffective for reducing worry (e.g., reassurance seeking, avoidance of worry triggers, thought suppression; Wells, 2004). The failure of these strategies to reduce worry ultimately reinforces the belief that worrying is uncontrollable and dangerous, which in turn may exacerbate anxiety (Behar et al., 2009; Moffitt, Harrington, et al., 2007; Valentiner et al., 2014).

Finally, avoidance and acceptance-based models of GAD suggest that worrying may be employed as a means of avoiding or modulating unwanted emotional experiences or internal sensations (Behar et al., 2009; Mennin et al., 2002). The evasion of emotional experiences is known as experiential avoidance (EA), and is also commonly seen in GAD (Chawla \& Ostafin, 2007). It has been suggested that people with GAD are more emotionally hyperaroused, uncomfortable with their intense emotional experiences, and utilize worry to minimize, control, or inappropriately express these emotions (Mennin, 2005). Similarly, acceptance-based conceptualizations of GAD highlight that people can find emotions threatening, and are motivated to escape these experiences through avoidance behaviours, and thoughts that enable avoidance (i.e., worry; Roemer \& Orsillo, 2005). Regardless of the model, EA contributes to greater experience of GAD in part because the cognitve act of worrying prevents the experiencing of somatic sensations and emotional processing of fear needed for individuals to habituate to and move past feared situations (Behar et al., 2009; Borkovec et al., 2004).

\subsection{Links Between PRD and Cognitive Processes of GAD}

Several aspects of the experience of PRD may exacerbate cognitive processes related to GAD. Although previously untested, we propose that there may be links between PRD and these 
processes. Consistent with recent longitudinal evidence (Smith et al., 2020), we believe that PRD may be impacting people's experience of mental illness, specifically the extent to which they experience anxiety and engage in thinking styles that contribute to anxiety. Experimental research has found that participants experience greater IU when the potential negative consequences of a situation are highlighted to them, or the uncertainty of a situation is made more salient (Ladouceur et al., 2000; Mosca et al., 2016). Accordingly, greater experience of PRD may increase IU, as the feelings of deprivation highlight the negative consequence of being at an unfair disadvantage in society, and may bring focus to uncertainty, such as surrounding the exact reasons why others are seemingly better off, or how to change one's relative standing. Moreover, negative experiences such as feeling deprived and resentful can contribute to people worrying (Beshai, Mishra, Mishra, et al., 2017; Lewis et al., 2017). Although previously

untested, we suggest that PRD may relate to meta-beliefs about this worry. Specifically, we hypothesize that people's positive beliefs about this worry may increase as they think it will help them resolve the negative situation. Similarly, people's negative beliefs about this worry may increase as they perceive worry as uncontrollable or dangerous. Finally, negative affect in the form of resentment, anger, and dissatisfaction may also relate to EA. That is, people may feel motivated to avoid such unpleasant emotional experiences, and thus increasingly engage in EA. Taken together, we believe that PRD will relate to greater experience of these cognitive processes, which will in turn relate to greater anxious symptomology.

\subsection{Psychosocial Correlates of GAD}

Although our focus is on cognitive processes that contribute to the experience of GAD, there are other psychological and social factors that may partly account for the experience of GAD. Firstly, lower self-efficacy (less confidence in one's abilities to succeed at a given task or 
achieve a goal) and poorer self-esteem (lower feelings of self-worth), have been associated with higher levels of GAD symptomology (Blanco et al., 2014; Muris, 2002; Sowislo \& Orth, 2013; Stanley et al., 2002). Similarly, GAD is highly comorbid with the experience of major depressive episodes and major depressive disorder (MDD), with lifetime comorbidity estimates suggesting that $46 \%$ of individuals with GAD will experience MDD (Ruscio \& Khazanov, 2017). While some of this comorbidity stems from overlap of diagnostic criteria, research shows that the comorbidity is in part due to shared vulnerability with associated psychosocial risk factors such as having less education and being unemployed (among other factors), and from shared personality characteristics (Zbozinek et al., 2012; Ruscio \& Khazanov, 2017). Key personality characteristics that are often shared among those with GAD and depression include neuroticism or negative affectivity (Brown \& Barlow, 2010). These traits reflect a tendency to experience negative affect to threat, frustration, or loss (Lahey, 2009).

\subsection{Present Research}

We propose that the tendency to feel relatively deprived compared to similar others may predispose people into engaging in problematic thinking, resulting in exacerbated GAD symptoms. In Study 1, we (a) explore associations between PRD and GAD in a previously collected multi-national sample; and (b) assess if IU, PBW, and/or NBW mediate the relationship between PRD and GAD symptoms. In Study 2, we replicate the analyses from Study 1 in a pre-registered US sample, with the addition of EA as a fourth potential mediator of associations between PRD and GAD.

Consistent with the literature reviewed and our reasoning above, we predicted that all four cognitive mechanisms (IU, PBW, NBW, and EA) would mediate associations of PRD and GAD. We also explored if expected associations between PRD and GAD would hold adjusting for a 
variety of background, socio-economic, self-concept, and mood variables. We included sex, age, education, and household income, as these have been shown to associate with GAD (Grant et al., 2009; Moffitt, Caspi, et al., 2007; Ruscio et al., 2017). We also included elements of selfconcept, including self-efficacy (Study 1) and self-esteem (Study 2) because they are important predictors of psychopathology symptoms, including GAD. A measure of perceived SES (Study 2) was included as lower perceived SES has been related to lower life satisfaction, and poorer mental health outcomes (Schneider, 2019). Finally, a measure of depression (Study 2) was also included as it has been related to both GAD and PRD (Beshai, Mishra, Meadows, et al., 2017; Kessler et al., 2008).

By testing these relationships across two studies we hope to provide initial evidence of whether the experience of personal deprivation consistently relates to the experience of GAD symptoms and how this may occur (see Nadler et al., 2020). As we argue that PRD may act as a potential risk factor for the development of GAD as a result of societal inequality, we have elected to capture community samples, rather than exclusively clinical participants, to explore whether these relationships may exist among the general population.

\section{Chapter 2: Study 1}

\subsection{Methods}

Prior to conducting the present research, the study procedure was reviewed and approved by the University of Regina's Research Ethics Board.

\subsubsection{Participants}

Study 1 participants $(n=748)$ were based on an existing dataset (see Beshai, Mishra, Meadows, et al., 2017) previously recruited through CrowdFlower, an online crowdsourcing platform (Goodman et al., 2013). CrowdFlower has been used in previous mental health research 
to provide reliable and valid data (Beshai, Mishra, Meadows, et al., 2017; Mishra \& Carleton, 2015). Participants primarily resided in the U.S., as well as in Canada, New Zealand, Australia, and the U.K. We excluded participants under 18 years of age $(n=2)$ and those that failed an attention check in which they were asked to provide a specific answer to a multiple-choice question $(n=158)$. This yielded a final sample of 588 participants whose demographic characteristics are roughly representative of the general U.S. adult population $\left(M_{\text {age }}=39.3\right.$ years [range 18 to 62 years old]; median household income $=$ US\$40,000-\$50,000), with a slightly greater proportion of women (57.6\% women) and individuals having completed a university degree (52.4\% completed university, college or higher education; (U.S. Census Bureau, 2018).

\subsubsection{Procedure and materials}

Participants provided consent for an online study on "Personality and Mental Health," and completed the following measures in random order, with questions within each measure also randomized. All measures were completed with higher numbers indicating greater experience of the construct. See Appendix A for full study materials.

Personal relative deprivation (PRD). Participants' subjective experience of deprivation was assessed using a 5-item measure ( $\alpha=0.83$; PRDS-R; Callan, Shead, $\&$ Olson, 2011). This measure evaluates feelings of deprivation, resentment, and dissatisfaction associated with comparing oneself to similar others (e.g., "I feel dissatisfied with what I have compared to what other people like me have") from 1 "strongly disagree" to 7 "strongly agree." It shows strong reliability and validity when used in similar populations and on similar platforms (see Mishra \& Meadows, 2018).

Intolerance of uncertainty (IU). The 12-item IUS-12 $(\alpha=0.91)$ assesses acceptance and reaction to the possibility of being exposed to ambiguous events (Carleton et al., 2007; Laugesen 
et al., 2003). Participants indicated how much they agreed that each statement is characteristic of their experience (e.g., "It frustrates me not having all the information I need") from 1 "not at all characteristic of me" to 5 "entirely characteristic of me." The IUS-12 has shown strong validity and internal consistency when used with non-clinical, community samples (Carleton et al., 2012).

Positive beliefs about worry $(\boldsymbol{P B W})$. A 6-item subscale $(\alpha=0.91)$ of the Metacognitions Questionnaire-30 (MCQ-30; Wells \& Cartwright-Hatton, 2004) was used to evaluate one's belief in the benefit of worry for solving one's problems (e.g., "Worrying helps me to avoid problems in the future") from 1 "do not agree" to 4 "agree very much.". The MCQ-30, and its subscales, have shown good reliability and validity when used in American community samples (Fergus \& Bardeen, 2017; Spada et al., 2008).

Negative beliefs about worry $(\mathrm{NBW})$. Another 6-item subscale $(\alpha=0.90)$ of the MCQ-30 was used to assess unfavorable beliefs about worrying thoughts, like the uncontrollability or dangerousness of worries (e.g., "My worrying is dangerous for me"; Wells \& Cartwright-Hatton, 2004) using the same scale as PBW.

Generalized anxiety disorder symptoms (GAD). The 7-item GAD-7 $(\alpha=0.92)$ assesses presence and severity of symptoms of GAD in accordance with the Diagnostic and Statistical Manual $4^{\text {th }}$ Edition (DSM-IV; American Psychological Association, 2013; Spitzer, Kroenke, Williams, \& Löwe, 2006), and has been validated for use in non-clinical populations (Löwe et al., 2017). Participants ranked the frequency with which they experienced symptoms (e.g., "Feeling nervous, anxious or on edge") from 0 "not at all" to 3 "nearly every day." The GAD-7 provides clinical cut-off scores in which scores between 5 and 9, 10 and 14, and 15 or more suggest mild, moderate, and severe symptoms of GAD, respectively (Spitzer et al., 2006). 
Self-efficacy (SEF). Participants' perception of their ability to achieve outcomes despite difficulties was measured using the 8 -item $(\alpha=.94)$ New General Self-efficacy Scale (e.g., "Even when things are tough, I can perform quite well;" NGSES; Chen, Gully, \& Eden, 2001). The NGSES places items on a 7 point scale from 1 "strongly disagree" to 7 "strongly agree" and has shown strong reliability and validity in a variety of samples (Chen et al., 2001; Scherbaum et al., 2006)

Demographics. Participants also answered questions about their sex, age, highest level of education, and household income, in addition to questions used for other research.

\subsubsection{Analysis}

For all central analyses, participants' scores on multi-item scales (i.e., for PRD, IU, PBW, NBW, GAD, self-efficacy) were calculated by averaging their responses across items. As the proportion of missing data was low (all participants completed greater than $93 \%$ of items), average scores include participants with missing data points. Participants who failed to provide responses for single-item variables (e.g., demographic information, subjective SES), were removed from analyses only for tests requiring this data (e.g., for mediations including these variables as covariates).

Consistent with the goal of examining a community sample, average GAD scores of the entire sample were used for all main analyses. However, to better understand the range of GAD symptom severity, participants' scores on the GAD-7 were also summed and compared to clinical cut-offs outlined by Spitzer et al. (2006). Mean total GAD scores were in the mild range $(M=5.86, S D=5.16)$, with $29.3 \%, 15.1 \%$ and $7.3 \%$ of the sample reporting mild, moderate and severe GAD symptoms respectively. This suggest that our sample experienced GAD symptoms 
in line with, or slightly more than the general population (Löwe et al., 2017; Spitzer et al., 2006; Valentiner et al., 2014).

We used a parallel, simultaneous mediation model to evaluate whether the cognitive predictors of GAD would mediate any relationship between PRD and GAD. Mediation analysis is a statistical method that can be used to help explain the process of how a predictor variable may transmit its effect through one or more intermediary variables on an outcome variable. Mediation provides information on both the direct, and indirect effect of the predictor variable on the outcome variable. The direct effect is a measure of the possible change in the outcome variable, given a one unit change in the predictor variable. The indirect effect is the measure of the possible change in the outcome variable, given a one unit change in the predictor variable, as a result of the effect of the predictor variable on the mediating variable (Hayes, 2018). In a multiple parallel mediation model, the indirect effect of multiple mediators is estimated while holding the other proposed mediators' effects constant. While our ability to determine causality is limited by our study design, this analysis can be used to test for relationships among variables in correlational designs (Hayes, 2018).

To conduct our mediation analysis, we followed a multiple-mediation percentile bootstrapping procedure with 5,000 resamples and a $95 \%$ confidence interval to simultaneously examine if cognitive processes accounted for significant indirect variance in the relation between PRD and GAD symptoms (Hayes, 2018; Preacher \& Hayes, 2008, PROCESS v3.3, model 4). As this was a first test of the potential relationships among all of our variables, and we did not have strong theoretical reasons to support a more complex model, we evaluated the effect of each variable simultaneously, rather than proposing a potentially more intricate relationship among them. For the purposes of interpretation, mediation is said to have occurred if there was a 
significant indirect effect of PRD on GAD through a mediator, as indirect effects can occur in the absence of a total effect (Hayes, 2018; Zhao et al., 2010). Furthermore, given that indirect effects can exist independent of a total effect, and in line with recent literature, we will discuss our results in terms of the evidence for "indirect" or "direct" effects, in lieu of using "partial" or “full” mediation (Hayes, 2018).

\subsection{Results and Discussion}

\subsubsection{Correlations}

We first examined zero-order correlations among the main study variables (see Table 1). The tendency to experience PRD was positively correlated with more severe GAD symptoms $(r$ $=.466, p<.001)$. Furthermore, PRD was positively correlated with all three mediating variables (IU, PBW, NBW; all $r \mathrm{~s}>.20, p \mathrm{~s}<.001$ ), and these mediating variables were positively related with each other and GAD symptoms (all $r \mathrm{~s}>.36, p s<.001)$.

Table 1: Means, standard deviations, and correlations among main variables, Study 1

\begin{tabular}{|c|c|c|c|c|c|c|}
\hline & $M(S D)$ & PRD & $\mathrm{IU}$ & PBW & NBW & GAD \\
\hline PRD & $3.58(1.20)$ & - & & & & \\
\hline IU & $2.84(0.80)$ & $.476 * * *$ & - & & & \\
\hline PBW & $1.74(0.67)$ & $.201 * * *$ & $.401 * * *$ & - & & \\
\hline NBW & $2.07(0.81)$ & $.424 * * *$ & $.681 * * *$ & $.381 * * *$ & - & \\
\hline GAD & $1.84(0.74)$ & $.466 * * *$ & $.611 * * *$ & $.364 * * *$ & $.741 * * *$ & - \\
\hline SEF & $5.04(1.06)$ & $-.550 * * *$ & $-.420 * * *$ & $-.114 * * *$ & $-.445 * * *$ & $-.464 * * *$ \\
\hline
\end{tabular}

\subsubsection{Mediation}

To explain the association of PRD and GAD, we conducted a simultaneous mediation analysis using PRD as the predictor variable, IU, PBW, and NBW as mediators, and GAD as the outcome variable. Based on the results of our correlation analysis and conceptual rationale, we assumed that there was a linear relationship among variables. Additionally, given the sample 
size, the variables were found to be sufficiently normally distributed for the proposed mediation tests (see Appendix B; Hayes, 2018; H.-Y. Kim, 2013). Based on multicollinearity tests we determined that the mediators could be considered independent of one another (see Appendix B). Our mediation analysis revealed that specific indirect effects of IU, PBW, and NBW, all significantly mediated the effect of PRD on experience of GAD symptoms (see Fig. 1). The total and direct effects of PRD on GAD were also significant. Post-hoc contrasts showed the specific indirect effect of NBW was significantly greater than IU, $b=.110$, CI $[.065, .159]$, which was in turn significantly greater than PBW, $b=.029$, CI [.003, .056].

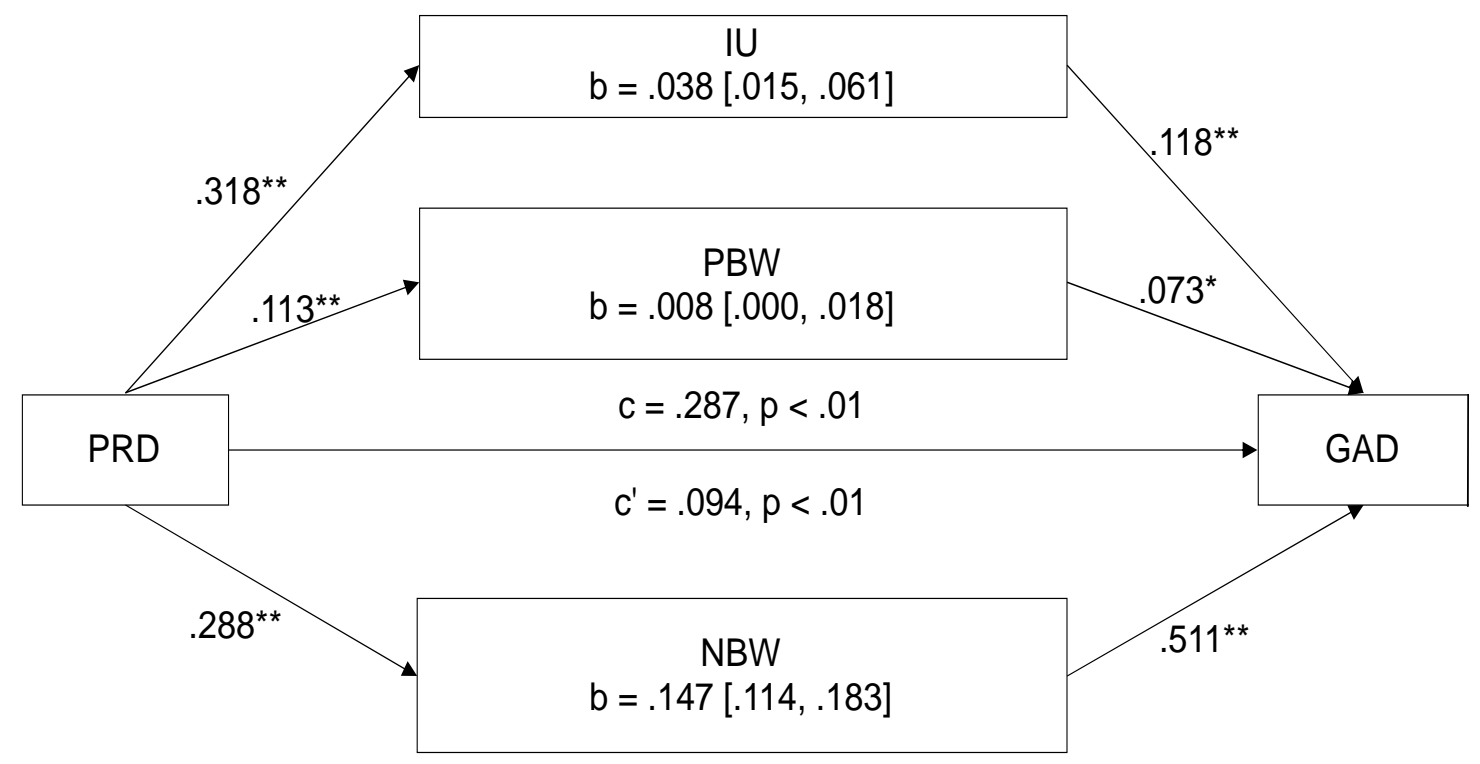

Figure 1. Mediation model of indirect effects of intolerance of uncertainty (IU), positive beliefs about worry (PBW), and negative beliefs about worry (NBW) on the relationship between personal relative deprivation (PRD) and symptoms of generalized anxiety disorder (GAD), Study 1. Values depict unstandardized regression coefficients, [95\% confidence intervals].

$* \mathrm{p}<.05 ; * * \mathrm{p}<.01$

In secondary analyses we examined the robustness of the above mediating model by first including sex, age, education, and household income as covariates. All pathways through the mediators remained significant with these factors included, as did the direct pathway of PRD on experience of GAD symptoms (see Appendix C for full model). Next, we included self-efficacy as the main control variable in the mediation model. This analysis again revealed significant 
indirect effects of all mediators: IU, $b=.025[.008, .045]$; PBW, $b=.010$, CI [.001, 020]; NBW, $b=.085$, CI $[.055, .119]$; with IU and NBW showing smaller indirect effects with the inclusion of self-efficacy relative to the initial mediation model. The total, $b=.260, p<.001$, and direct, $b$ $=.096, p<.001$, effects of PRD on GAD remained significant.

\subsubsection{Study 1 Discussion}

The results of Study 1 provide preliminary and novel evidence that PRD may relate to the experience of GAD symptoms, and that this relationship may be in part explained by known cognitive predictors of GAD. Specifically, the positive association between PRD and GAD was partially explained by IU, PBW, and NBW, such that PRD related to higher IU, PBW, and NBW, which in turn related to greater symptoms of GAD. These results held when controlling for several sociodemographic variables, suggesting that the results are not only explained by objective indicators of status, such as education or income. Moreover, when controlling for selfefficacy, mediating variables showed less explanatory power, suggesting that an individual's perception of their ability to succeed despite difficulties may account for some variance in the experience of GAD symptoms otherwise explained by other model variables. The results of Study 1, however, are limited by the fact that we did not include a measure of perceived SES, a known predictor of mental health outcomes, nor mental health constructs related to anxiety such as self-esteem and depression. We address these limitations in Study 2.

\section{Chapter 3: Study 2}

Study 2 sought to examine whether the pattern of findings observed in Study 1 would replicate in a separate, preregistered sample, and if a fourth proposed psychological mediator, experiential avoidance (EA), would explain the relation between the experience of PRD and GAD symptoms beyond the three mediators in Study 1. 
To further test the robustness of our expected findings we also added three control measures: perceived SES; self-esteem, which has been related to lesser symptoms of mental illness; and self-report symptoms of depression, another mental disorder with which generalized anxiety is highly correlated (Ruscio et al., 2017).

\subsection{Methods}

Prior to conducting the present research, the study procedure was reviewed and approved by Memorial University's Interdisciplinary Committee on Ethics in Human Research (ICEHR Approval \# 20192246-SC).

\subsubsection{Participants}

Following our preregistration plan and with consideration to financial limitations we targeted a sample of $n=300$ in order to achieve roughly $80 \%$ power. The sample size was partly based on simulations done by Fritz \& MacKinnon (2010) and the assumption that the indirect pathways in our mediation model would produce small to medium effects such as in Beshai, Mishra, Meadows et al. (2017). We recruited an online sample of 305 American residents through Prolific Academic's crowdsourcing platform, in order to better compare to other research in this area with primarily American samples. Prolific has been recognized as providing diverse, attentive samples of individuals who respond reasonably to study content, comparable to other crowdsourcing services (Peer et al., 2017). Participants consented to take part in a survey about "Societal Beliefs and Mental Health," and were compensated approximately \$1.00 U.S. We excluded participants according to the following pre-registered criteria: failing to complete $50 \%$ of all questions $(n=4)$, taking less than 3 minutes to complete all study measures (e.g., to remove participants who "clicked-through"), or being under 18 years of age. The final sample included 301 participants $\left(M_{\text {age }}=34.8\right.$ years [range 18 to 75 years old] $)$, of which $51.0 \%$ 
identified as women, $79.7 \%$ identified as White, $50.5 \%$ completed an undergraduate degree or greater, with reported median income between US\$45,000-\$60,000.

\subsubsection{Procedure and materials}

Participants completed the same measures as in Study 1. PRD and perceived SES appeared in a randomized order, followed by the mediators in this order: PBW, IU, EA, NBW, or its reverse. After, participants completed measures of GAD symptomology and self-esteem, measures unrelated to the present study, and finally, demographic questions. All measures were completed with higher numbers indicating greater experience of the construct.

Measures showed good reliability with the current sample: Personal Relative Deprivation (PRD; 5 -items; $\alpha=.84$ ); Generalized Anxiety Disorder (GAD; 7-items; $\alpha=.93$ ); Intolerance of Uncertainty (IU; 12-items; $\alpha=.89$ ); Positive Beliefs about Worry (PBW; 6-items; $\alpha=.90$ ); and Negative Beliefs About Worry (NBW; 6-items; $\alpha=.95$ ). While all instructions and item phrasing remained identical for all measures, some scales for these measures differed slightly in the scales used from Study 1 to Study 2 in order for the scales responses among mediators to remain as consistent as possible throughout Study 2. Specifically, the scales for measures of PBW and NBW changed from a 4-point to a 7-point scale, the scale for IU was changed from a 5-point to a 7-point scale. and the anchors changed for the measure of IU (see the Appendix D for all study

materials). Clinical symptom scales (e.g., GAD-7 and PHQ-8) retained their original structure to accurately reflect diagnostic criteria and severity. Additional measures were as follows:

Experiential avoidance (EA): The Brief Experiential Avoidance Questionnaire (BEAQ) was used to assess the tendency to avoid one's internal experiences (i.e., thoughts, feelings) (Gámez et al., 2014). The 15-item questionnaire ( $\alpha=0.86$ ) assesses beliefs about behavioural avoidance, distress aversion and endurance, procrastination, and distraction (e.g., "I work hard to 
keep out upsetting feelings"), on a 7-point scale from 1 "strongly disagree" to 7 "strongly agree." It has been validated in use in both clinical and non-clinical populations (Gámez et al., 2014).

Perceived SES: This widely used measure assesses participants' subjective view of their place in the social hierarchy, represented by a picture of a ladder (Adler et al., 2000; Operario et al., 2004). Participants placed themselves from 1 (lowest in the hierarchy) to 10 (highest in the hierarchy) on the ladder.

Self-esteem (SE): The 10-item Rosenberg measure $(\alpha=0.94)$ assesses one's general feelings and attitudes about themselves (e.g., "On the whole, I am satisfied with myself") on a scale from 1 "strongly disagree" to 7 "strongly agree.". It is one of the most widely used measures of self-esteem (Sinclair et al., 2010).

Depressive symptoms: The Patient Health Questionnaire - 8 (PHQ-8) is an eight-item measure that assesses presence and severity of major depressive disorder symptoms in accordance with DSM-5 criteria (e.g., "Little interest or pleasure in doing things") from on a scale from 0 "not at all" to 4 "nearly every day". The PHQ-8 is the shortened version of the PHQ-9, with a question about suicidality removed, chosen because we were unable to probe positive responses to this item. It has been validated as a reliable measure of depressive symptoms in the general population (Kroenke et al., 2009).

Demographics: Similar to Study 1, participants provided gender (rather than sex), age, education, and household income. Participants also indicated their ethnicity and provided additional background information for use in other research.

\subsubsection{Analysis}

All analytical methods were the same as in Study 1. Again, as the proportion of missing data was low (one participant completed approximately $91 \%$ of items, and all others completed 
greater than $98 \%$ of all items), participants' average scores on multi-item scales include missing data points. As in Study 1, we assumed our variables had a linear relationship, and found that they could be considered independent (see Appendix E). The GAD-7 showed small deviations from normality (H.-Y. Kim, 2013; see Appendix E), which is consistent with other studies utilizing this measure in non-clinical samples (e.g., Löwe et al., 2017). However, the bootstrap method is robust to violations of normality if the sample is reasonably representative of the population (Hayes, 2018). The proportion of our sample that endorsed GAD symptoms was above rates of GAD found in the general population $(M=7.10, S D=5.81$; Haller et al., 2014;

Löwe et al., 2017), as $31.8 \%$ of participants' symptoms were rated as "mild," $16.8 \%$ as "moderate," and $13.1 \%$ as "severe." Accordingly, we did not transform data for our analyses.

\subsection{Results and Discussion}

\subsubsection{Correlations}

First, we examined the zero-order correlations among the key study variables (Table 2). As in Study 1, PRD was related to greater experience of GAD symptoms, $r=.366, p<.001$. Additionally, PRD was positively related to all four mediating variables (all $r \mathrm{~s}>.13, p s<.05$ ). All mediating variables were positively related to each other and GAD symptoms (all $r \mathrm{~s}>.24, p \mathrm{~s}$ $<.001)$. 
Table 2: Means, standard deviations, and correlations of main study variables, Study 2

\begin{tabular}{|c|c|c|c|c|c|c|c|c|c|}
\hline & $M(S D)$ & PRD & $\mathrm{IU}$ & PBW & NBW & EA & GAD & PSES & $\mathrm{SE}$ \\
\hline PRD & $3.49(1.25)$ & - & & & & & & & \\
\hline IU & $4.30(1.08)$ & $.366 * * *$ & - & & & & & & \\
\hline PBW & $3.26(1.35)$ & $.132 *$ & $.295 * * *$ & - & & & & & \\
\hline NBW & $3.91(1.70)$ & $.344 * * *$ & $.619 * * *$ & $.295 * * *$ & - & & & & \\
\hline EA & $3.74(0.93)$ & $.415 * * *$ & $.683 * * *$ & $.240 * * *$ & $.615 * * *$ & - & & & \\
\hline GAD & $1.01(0.83)$ & $.366 * * *$ & $.579 * * *$ & $.263 * * *$ & $.761 * * *$ & $.542 * * *$ & - & & \\
\hline PSES & $5.32(1.71)$ & $-.396 * * *$ & $-.226 * * *$ & .063 & $-.132 * *$ & $-.133 *$ & $-.193 * * *$ & - & \\
\hline SE & $5.32(1.71)$ & $-.473 * * *$ & $-.502 * * *$ & $.167 * * *$ & $-.667 * * *$ & $-.578 * * *$ & $-.664 * * *$ & $.315 * * *$ & - \\
\hline DEP & $0.92(0.78)$ & $.370 * *$ & $.538 * *$ & $.219 * *$ & $.677 * *$ & $.548 * *$ & $.837 * *$ & $-.231 * *$ & $-.728 * *$ \\
\hline
\end{tabular}

Note. $* p<.05, * * p<.01, * * * p<.001$

Note: $\mathrm{PRD}=$ personal relative deprivation, $\mathrm{IU}=$ intolerance of uncertainty, $\mathrm{PBW}=$ positive beliefs about worry, NBW= negative beliefs about worry, $\mathrm{IU}=$ intolerance of uncertainty, $\mathrm{EA}=$ experiential avoidance, GAD = generalized anxiety disorder symptoms, PSES = perceived socioeconomic status; SE = self-esteem; $\mathrm{DEP}=$ symptoms of depression

\subsubsection{Mediation}

To directly replicate analyses from Study 1, we constructed a mediation model with three mediators (IU, PBW, NBW) linking PRD and GAD symptomology. Using identical procedures, this analysis partly replicated findings of Study 1 . The specific indirect effects of IU, $b=.036$, CI $[.001, .066]$, and NBW, $b=.144$, CI $[.093, .197]$, significantly mediated the relationship between PRD and experience of GAD symptoms. However, the specific indirect effect of PBW did not, $b$ $=.002$, CI $[-.006, .011]$. As in Study 1, the total effect of PRD on GAD, $b=.242, p<.001$, was significant, as was the direct effect of PRD on GAD, $b=.060, p=.023$. Also consistent with Study 1 , the indirect effect of NBW was significantly greater than that of IU, $b=.108$, CI [.050, $.170]$, and the indirect effect of IU was greater than PBW, $b=-.034$, CI [-.067, -.007]. Moreover, indirect effects of IU and NBW remained significant when the same covariates as in Study 1 (age, gender, household income, and education) were added as controls to the mediation model (see Appendix F). Together, these results mostly replicate findings of Study 1.

Next, EA was added to the mediation model to test whether the relation between PRD and GAD symptoms was mediated by the four proposed cognitive processes. This mediation analysis 
revealed that the specific indirect effects of IU and NBW significantly mediated the association between PRD and GAD symptoms, however the specific indirect effects of PBW and EA did not. The total and direct effects of PRD on GAD symptoms were significant (see Fig. 2). We also examined the same four-mediator model when controlling for the background variables used in Study 1, along with participant ethnicity. Including these control variables did not significantly alter the results (see Appendix F).

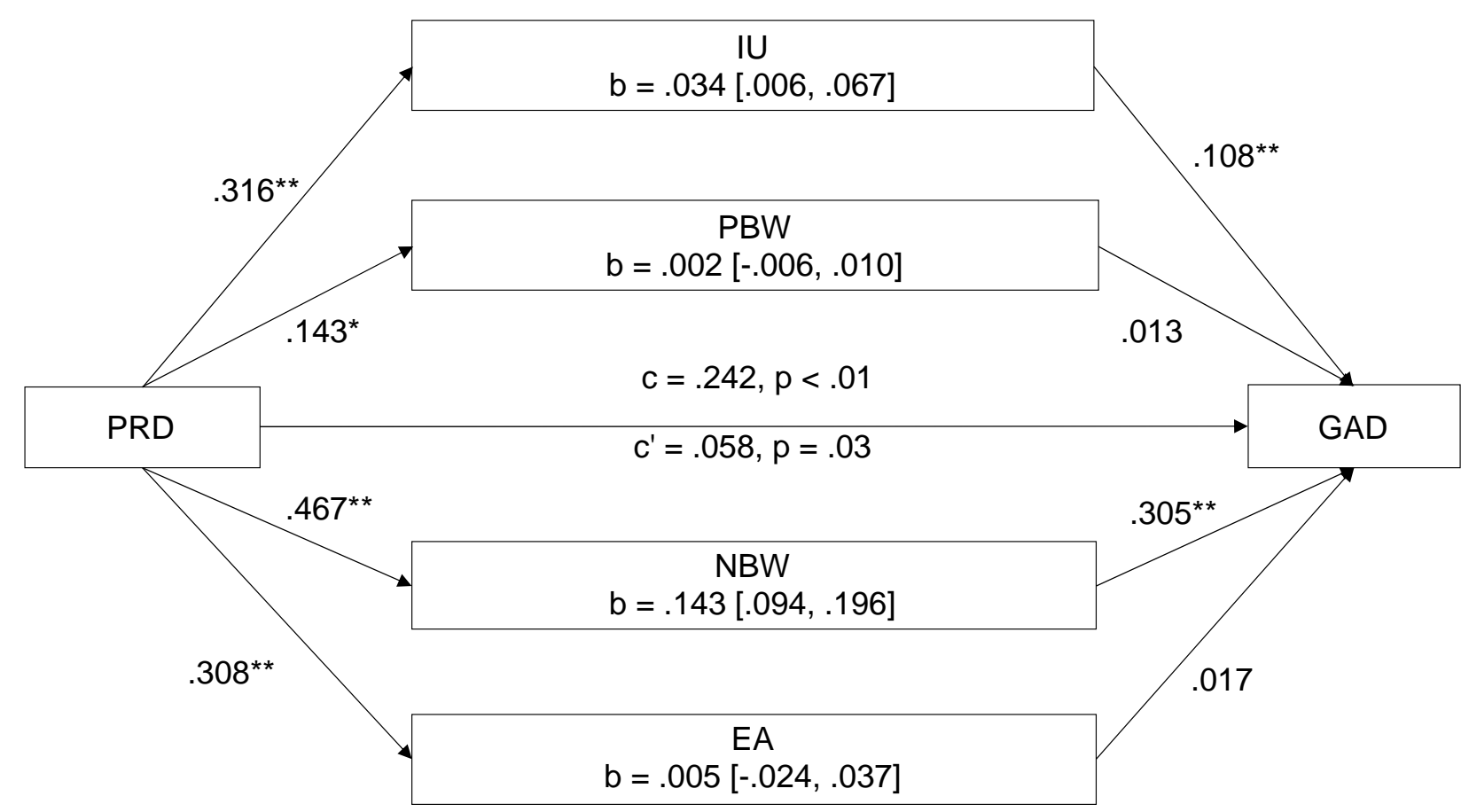

Figure 2. Mediation model showing indirect effect of IU, PBW, NBW, and experiential avoidance (EA) on the relationship between PRD and symptoms GAD, Study 2. Values depict unstandardized regression coefficients, [95\% confidence intervals]. $* \mathrm{p}<.05 ; * * \mathrm{p}<.01$

Finally, to further test the robustness of the results, we ran the four-mediator model three times, separately adding perceived SES, self-esteem, and symptoms of depression as covariates. When perceived SES was added to the model, the specific indirect effects of IU, $b=.028, \mathrm{CI}$ $[.003, .057]$, and NBW, $b=.144$, CI $[.088, .198]$, mediated the PRD-GAD relationship, while the 
specific indirect effects of other mediators were non-significant. The total effect of PRD on GAD was significant, $b=.227, p<.001$, but the direct effect of PRD on GAD was not, $b=.044, p=$ .126. When self-esteem was added to the four-mediator model, the indirect effect of IU remained significant, $b=.016$, CI [.002, .035], but the indirect effect of NBW did not, $b=.013$, CI [-.022, $.050] . \mathrm{PBW}, b=.002$, CI [-.003, .008], and EA, $b=-.004$, CI [-.019, .011], remained nonsignificant. While the total effect, $b=.046, p=.161$, and direct effect, $b=.020, p=.460$, of PRD on GAD were not significant, the significant indirect effect through IU indicates that mediation still occurred (Zhao et al., 2010). When symptoms of depression were added to the model, the specific indirect effect of NBW, $b=.024$ CI $[.004, .048]$, mediated the PRD-GAD relationship, while the specific indirect effects of the other mediators were non-significant. The total effect of PRD on GAD approached significance, $b=.043, p=.055$, and the direct effect of PRD on GAD was not significant, $b=.017, p=.416$. Again, the significant indirect effect through a mediator (NBW) indicates that mediation occurred.

\subsubsection{Study 2 Discussion}

Consistent with Study 1, in Study 2 we demonstrated a relationship between the experiences of PRD and anxiety symptoms. Whereas in Study 1 higher levels of three processes (IU, PBW, and NBW) helped explain this association, in Study 2 only two of these (IU and NBW) were significant. When the fourth proposed mediator, EA, was added to the mediation model in Study 2, IU and NBW continued to mediate the relationship between PRD and GAD, while EA and PBW did not. These results were also robust to the inclusion of several demographic variables as well as perceived SES, a known predictor of health and well-being outcomes that involves elements of social comparison. Taken together, these findings suggest that PRD relates to GAD symptoms beyond indicators of one's objective and subjective place in 
the social hierarchy. The inclusion of self-esteem and symptoms of depression as covariates relatively weakened the explanatory power of the mediators. Although IU remained significant with the inclusion of self-esteem, the indirect role of NBW became indistinguishable from zero. This finding, though exploratory, suggests that consideration of global evaluations of self (i.e., through self-efficacy or self-esteem) may be useful when examining GAD-related predictors and underlying processes. With the inclusion of symptoms of depression, NBW continued to mediate the relationship between PRD and GAD, while IU did not. These exploratory findings further suggest that PRD may share a unique relationship with GAD. We return to these points in the next section.

\section{Chapter 4: General Discussion}

\subsection{Findings}

People commonly interact with, notice, and think about similar others. Almost inevitably, some social comparison will occur, during which many may feel that they are relatively deprived and deserve to have more (H. Kim et al., 2018). Societal conditions, such as inequality, can intensify this dissatisfying experience, and over time, the tendency to feel deprived may be problematic for people's well-being (Callan, Kim, et al., 2015b; Smith et al., 2012; Smith et al., 2020). The present research examined contributions of feeling deprived compared to similar others to explaining symptoms of generalized anxiety disorder (GAD). Across two studies, we demonstrated novel and consistent evidence of association between personal relative deprivation (PRD) and symptoms of generalized anxiety disorder. Our results suggest that the tendency to experience personal relative deprivation may "trap" people in thinking patterns that contribute to experiences of anxiety. 
Intolerance of uncertainty (IU) and negative beliefs about worry (NBW) consistently explained part of the relationship between PRD and symptoms of GAD. The indirect effects of IU and NBW held independent of key demographic predictors of mental health, including objective and subjective indicators of socioeconomic status (Adler et al., 2000; Rivenbark et al., 2020; Singh-Manoux et al., 2003). Critically, the relation of PRD to IU and NBW, in addition with other findings about potential impact of PRD on poorer mental health (e.g., Callan, Kim, et al., 2015b; Smith et al., 2020) suggest that PRD could act as an instigative factor for the development or maintenance of generalized anxiety, though our study design limits our ability to infer causality (Dugas et al., 2005; Penney et al., 2013; Ruscio \& Borkovec, 2004). While further research is needed, this may provide preliminary evidence that exploring feelings of deprivation with patients may help clinicians better understand or conceptualize their experience of GAD. The results of our research are also consistent with other demonstrated links between PRD and negative mental health outcomes (e.g., symptoms of depression, higher levels of stress; Beshai, Mishra, Meadows, et al., 2017; Callan, Kim, et al., 2015b), and between PRD and cognitive processes that contribute to psychopathology (e.g., negative automatic thoughts about the self, dysfunctional attitudes; Beshai, Mishra, Meadows, et al., 2017).

The association between PRD and GAD was not explained through an individual's positive beliefs about their worry (PBW), or through avoidance of unwanted emotional experiences (EA). The failure of PBW to mediate the relationship between PRD and GAD symptoms ran counter to our hypotheses. In examining the direct effects, this result may be partly explained by the relatively weaker associations between engaging in PBW and experiencing GAD symptoms, rather than associations between PRD and PBW (see Appendix F for select models with all effects included). This shows some consistency with the metacognitive 
theory that suggests that PBW predicts NBW, which in turn predicts experience of GAD (in contrast to our model that evaluated their role in predicting GAD symptoms simultaneously; Wells, 2005). This is also consistent with the finding that PBW is more specifically associated with trait worry rather than with more specific symptoms of GAD (e.g., irritability, tension; Penney et al., 2013). Additionally, while the presence of GAD symptoms in our sample was largely consistent with the prevalence of GAD in the general population, the wide range of symptom presentation included some individuals who did not experience symptoms of GAD that would suggest the presence of diagnosible disorder (Spitzer et al., 2006). While the greater range of presentations may alter the observered strength of the relationships between GAD and its cognitive predictors, it suggests that our results may be generalizable to people with a wide range of symptom severity.

Similarly, EA had a relatively weaker relationship to GAD, but was significantly related to PRD. We initially hypothesized that resentment and anger typically inherent in PRD may contribute to experiential avoidance, and in turn GAD symptoms. The weak association observed may be rooted in the inconsistent relationship between avoidance of anger and GAD (Buhr \& Dugas, 2012; Roemer et al., 2005). Further research into the consistency of the contribution of EA to GAD symptoms may help shed light on our findings.

The inclusion of variables that reflect self-concept evaluations reduced the strength of the relationship between PRD and symptoms of GAD through the proposed mediators. When selfefficacy was controlled for in Study 1, the strength of all the mediators was reduced but remained significant. When self-esteem was controlled for in Study 2, only IU helped explain the PRD-GAD relationship. These results suggest that while IU and NBW partly explained the relationship between PRD and GAD in both studies, evidence for the unique role of NBW in this 
relationship is weak. Consistent with prior research, we treated self-esteem as a stable trait predictor of psychological disorders, but some evidence suggests that PRD may negatively affect self-esteem momentarily as well as over time (Osborne et al., 2015; Walker, 1999). Plausibly, lower self-esteem may also influence engaging in PRD, which combined, suggests a potentially more complex relationship amongst our variables. Although the present research focused on cognitive processes relevant to PRD and GAD, it may be useful to clarify the potential roles of self-concept factors in the design of future research on PRD and mental health related outcomes.

Similarly, the inclusion of symptoms of depression as a covariate reduced the strength of the relationship between PRD and GAD symptoms. NBW continued to mediate the relationship, while IU and the other mediators did not. This finding is consistent with research that shows that IU may be a transdiagnostic risk factor for multiple disorders, including GAD and depression, while NBW may be more specific to GAD (Yook et al., 2010). This result suggests that PRD may be related to unique symptoms and experiences of GAD (e.g., feeling nervous, anxious, uncontrollable worry, rather than to symptoms of GAD shared with depression (e.g., concentration difficulties, feeling restless). Furthermore, this finding suggests the possibility that the association of PRD with GAD symptoms may not be due to shared characteristics such as negative affectivity, though further research is clearly needed (Kessler et al., 2008).

\subsection{Limitations and Implications}

Our studies have limitations that provide questions for further research. First, the correlational nature of our research limits our ability to draw causal inferences. Future research could employ longitudinal or experimental study designs in order test the possibility that PRD increases GAD symptoms (and explore processes involved therein). Moreover, the parallel mediation model assumes that no mediator has a causal effect on another. While we found our 
variables to be independent from one another, our proposed mediators in practice may partly impact one another (Behar et al., 2009; Richard G. Heimberg et al., 2004). Our models therefore tested one of a number of possible models for explaining the relationship between PRD or GAD, and future research may test additional models that capture the potential complex relationships among our study variables. Second, our study used self-report measures of symptoms of GAD and associated cognitive processes. Although these measures are frequently used in research and have strong psychometric properties, they lack sensitivity and specificity of a clinical interview. Thus, future research with varied measurement techniques could increase confidence in the PRD and GAD association and the indirect processes that appear to be involved. Third, while our research benefited from the consistency of having two reasonably sized Western samples with representative levels of GAD symptomology that facilitated comparison across studies, it would be illuminating to examine if the findings of the present study generalize to more demographically representative and diverse samples, as the present samples were a self-selecting sample of primarily White (Study 2), educated, and employed participants. For example, it may be particularly interesting to examine if factors such as societal inequality and cultural values factors likely to influence PRD — moderate the results (Smith et al., 2018). Similarly, given participants from both samples primarily resided in the United States, it would be illuminating to see if these results held in a Canadian sample. Additionally, our studies aimed to capture the experience of individuals drawn from the general population. Although the majority of participants in both studies reported some symptoms of GAD, a large proportion endorsed mild or no symptoms. As our sample size limited our ability to run analyses only on those experiencing moderate or severe symptoms, it would be illuminating to explore the associations among our variables in a more specific clinical sample. Fourth, we did not include a number of 
potential related variables that may help to further explain the relationship between PRD and GAD. Social comparison, for example, is a key component of PRD and future research may seek to test to what extent a tendency to socially compare may moderate the relationship between PRD and GAD. Likewise, as cognitions associated with depression have been shown to be related to PRD there may be additional cognitive predictors, such as cognitive fusion and rumination, that help to explain the relationship between PRD and GAD or other mental health outcomes (Nasiri et al., 2019; Yook et al., 2010). Fifth, while the proportion of missing data, attention checks (e.g., requiring a specific response), and exclusion criteria (e.g., removing participants who "clicked-through") suggest that participants were attentive while completing the survey, participant response styles and biases as well as common method variance may have reduced the accuracy of the data collected, or artificially inflated correlations.

This research adds to a growing body of evidence suggesting that PRD is a powerful predictor of mental health and well-being, and thus has several possible implications for research, individual experiences, and societal experiences. As an example, PRD may provide unique insight into the experience of social anxiety given that, similar to GAD, it appears to be partly grounded in intolerance of uncertainty (Boelen \& Reijntjes, 2009). At the individual level, our research may provide insight into researching treatments for GAD by altering cognitions associated with PRD. The tendency to feel relatively deprived when comparing to others may exacerbate dysfunctional cognitions associated with mental illness. Accordingly, mental health practitioners may find it fruitful to evaluate whether relative deprivation is a potential risk factor during clinical treatment. Finally, our research has potential implications at the systemic or societal levels. Feeling relatively deprived may in part be the result of unequal or competitive systems (e.g., societal systems of high inequality, or unequal pay; Osborne et al., 2012; Sweeney 
et al., 1990). For example, greater initial PRD in a longitudinal study of undergraduate students was found to mediate the relationship between lower self-reported income, and poorer mental health outcomes two years later (Smith et al., 2020). Consequently, it may be possible to partly reduce the experience of deprivation (and downstream mental health consequences) through policy changes that decrease unfair inequalities and competition. Research exploring the impact of policies that aim to address these systemic issues is limited, mixed, and may be complicated by a number of factors (e.g., tendencies to justify current economic systems; see Goudarzi et al., 2020; Wahlbeck et al., 2017), highlighting that additional research is required to examine these possibilities. 


\section{References}

Adjaye-Gbewonyo, K., \& Kawachi, I. (2012). Use of the Yitzhaki Index as a test of relative deprivation for health outcomes : A review of recent literature. Social Science \& Medicine, 75(1), 129-137. https://doi.org/10.1016/j.socscimed.2012.03.004

Adler, N. E., Epel, E. S., Castellazzo, G., \& Ickovics, J. R. (2000). Relationship of Subjective and Objective Social Status With Psychological and Physiological Functioning : Preliminary Data in Healthy White Women. Health Psychology, 19(6), 586-592. https://doi.org/10.1037//0278-6133.19.6.586

American Psychological Association. (2013). Diagnostic and statistical manual of mental disorders (5th ed.). Author.

Behar, E., DiMarco, I. D., Hekler, E. B., Mohlman, J., \& Staples, A. M. (2009). Current theoretical models of generalized anxiety disorder (GAD): Conceptual review and treatment implications. Journal of Anxiety Disorders, 23(8), 1011-1023. https://doi.org/10.1016/j.janxdis.2009.07.006

Bernstein, M., \& Crosby, F. (1980). An empirical examination of relative deprivation theory. Journal of Experimental Social Psychology, 16(5), 442-456. https://doi.org/10.1016/00221031(80)90050-5

Beshai, S., Mishra, S., Meadows, T. J. S., Parmar, P., \& Huang, V. (2017). Minding the gap: Subjective relative deprivation and depressive symptoms. Social Science \& Medicine, 173, 18-25. https://doi.org/10.1016/j.socscimed.2016.11.021

Beshai, S., Mishra, S., Mishra, S., \& Carleton, N. R. (2017). Personal relative deprivation associated with functional disorders via stress: An examination of fibromyalgia and gastrointestinal symptoms. PLoS ONE, 12(12), 1-14. https://doi.org/10.1371/journal.pone.0189666

Blanco, C., Rubio, J., Wall, M., Wang, S., Jiu, C. J., \& Kendler, K. S. (2014). Risk factors for anxiety disorders: Common and specific effects in a national sample. Depression and Anxiety, 31(9), 756-764. https://doi.org/10.1002/da.22247

Boelen, P. A., \& Reijntjes, A. (2009). Intolerance of uncertainty and social anxiety. Journal of Anxiety Disorders, 23(1), 130-135. https://doi.org/10.1016/j.janxdis.2008.04.007

Bono, R., Blanca, M. J., Arnau, J., \& Gómez-Benito, J. (2017). Non-normal distributions commonly used in health, education, and social sciences: A systematic review. Frontiers in Psychology, 8(SEP), 1-6. https://doi.org/10.3389/fpsyg.2017.01602

Borkovec, T. D., Alcaine, O. M., \& Behar, E. (2004). Avoidance Theory of Worry and Generalized Anxiety Disorder. In Richard G. Heimberg, C. L. Turk, \& D. S. Mennin (Eds.), Generalized anxiety disorder: Advances in research and practice (pp. 77-108).

Boswell, J. F., Thompson-Hollands, J., Farchione, T. J., \& Barlow, D. H. (2014). Intolerance of uncertainty: A common factor in the treatment of emotional disorders. Journal of Clinical Psychology, 69(6), 1-16. https://doi.org/10.1002/jclp.21965.Intolerance

Brown, T. A., \& Barlow, D. H. (2010). A proposal for dimensional classification system based on the shared features of the DSM-IV anxiety and mood disorders: Implications for assessment and treatment. 21(3), 256-271. https://doi.org/10.1037/a0016608.A

Buhr, K., \& Dugas, M. J. (2006). Investigating the construct validity of intolerance of uncertainty and its unique relationship with worry. Journal of Anxiety Disorders, 20(2), 222-236. https://doi.org/10.1016/j.janxdis.2004.12.004

Bureau, U. S. C. (2018). Educational Attainment in the United States: 2018. 
Buttrick, N. R., \& Oishi, S. (2017). The psychological consequences of income inequality. Social and Personality Psychology Compass, 11(3), e12304. https://doi.org/10.1111/spc3.12304

Callan, M. J., Kim, H., \& Matthews, W. J. (2015a). Age differences in social comparison tendency and personal relative deprivation. Personality \& Individual Differences, 87, 196199. https://doi.org/10.1016/j.paid.2015.08.003

Callan, M. J., Kim, H., \& Matthews, W. J. (2015b). Predicting self-rated mental and physical health: the contributions of subjective socioeconomic status and personal relative deprivation. Frontiers in Psychology, 6(6). https://doi.org/10.3389/fpsyg.2015.01415

Callan, M. J., Shead, N. W., \& Olson, J. M. (2011). Personal relative deprivation, delay discounting, and gambling. Journal of Personality and Social Psychology, 101(5), 955-973. https://doi.org/10.1037/a0024778

Callan, M. J., Will Shead, N., \& Olson, J. M. (2015). The relation between personal relative deprivation and the urge to gamble among gamblers is moderated by problem gambling severity: A meta-analysis. Addictive Behaviors, 45, 146-149. https://doi.org/10.1016/j.addbeh.2015.01.031

Carleton, N. R., Mulvogue, M. K., Thibodeau, M. A., McCabe, R. E., Antony, M. M., \& Asmundson, G. J. G. (2012). Increasingly certain about uncertainty: Intolerance of uncertainty across anxiety and depression. Journal of Anxiety Disorders, 26(3), 468-479. https://doi.org/10.1016/j.janxdis.2012.01.011

Carleton, N. R., Norton, P. J., \& Asmundson, G. J. G. (2007). Fearing the unknown: A short version of the Intolerance of Uncertainty Scale. Journal of Anxiety Disorders, 21(1), 105117. https://doi.org/10.1016/j.janxdis.2006.03.014

Chawla, N., \& Ostafin, B. (2007). Experiential avoidance as a functional dimensional approach to psychopathology: An empirical review. Journal of Clinical Psychology, 63(9), 871-890. https://doi.org/10.1002/jclp.20400

Chen, G., Gully, S. M., \& Eden, D. (2001). Validation of a New General Self-Efficacy Scale. Organizational Research Methods, 4(1), 62-83. https://doi.org/10.1177/109442810141004

Cheung, F., \& Lucas, R. E. (2016). Income inequality is associated with stronger social comparison effects: The effect of relative income on life satisfaction. Journal of Personality and Social Psychology, 110(2), 332-341. https://doi.org/10.1037/pspp0000059

Crosby, F. (1976). A model of egoistical relative deprivation. Psychological Review, 83(2), 85113. https://doi.org/10.1037/0033-295X.83.2.85

Crosby, F. (1982). Relative deprivation and working women. Oxford University Press.

Delhey, J., \& Dragolov, G. (2014). Why inequality makes europeans less happy: The role of distrust, status anxiety, and perceived conflict. European Sociological Review, 30(2). https://doi.org/10.1093/esr/jct033

Dückers, M. L. A., Alisic, E., \& Brewin, C. R. (2016). A vulnerability paradox in the crossnational prevalence of post-traumatic stress disorder. British Journal of Psychiatry, 209(4), 300-305. https://doi.org/10.1192/bjp.bp.115.176628

Dugas, M. J., Buhr, K., \& Ladouceur, R. (2004). The role of intolerance of uncertainty in etiology and maintenance. In R.G Heimberg, C. L. Turk, \& D. S. Mennin (Eds.), Generalized anxiety disorder: Advances in research and practice (pp. 143-163). Guilford Press.

Dugas, M. J., Marchand, A., \& Ladouceur, R. (2005). Further validation of a cognitivebehavioral model of generalized anxiety disorder: Diagnostic and symptom specificity. Journal of Anxiety Disorders, 19(3), 329-343. https://doi.org/10.1016/j.janxdis.2004.02.002 
Ehsan, A. M., \& De Silva, M. J. (2015). Social capital and common mental disorder: A systematic review. Journal of Epidemiology and Community Health, 69(10), 1021-1028. https://doi.org/10.1136/jech-2015-205868

Fagerland, M. W. (2012). Studies - a Paradox of Statistical Practice ? Medical Research Methodoligy, 12:78.

Fergus, T. A., \& Bardeen, J. R. (2017). The Metacognitions Questionnaire-30: An Examination of a Bifactor Model and Measurement Invariance Among Men and Women in a Community Sample. Assessment, January, 1-12. https://doi.org/10.1177/1073191116685807

Filho, A. D. P. C., Kawachi, I., Pang Wang, Y., Carmen Viana, M., Helena Silveira Guerra Andrade, L., \& Dias Porto, A. (2013). Does income inequality get under the skin? A multilevel analysis of depression, anxiety and mental disorders in São Paulo, Brazil. Source: Journal of Epidemiology and Community Health Journal of Epidemiology and Community Health, 67(11), 966-972. https://doi.org/10.1136/jech-2013-202626

Fritz, M. S., \& MacKinnon, D. P. (2010). Required sample size to detect the mediated effect. Psychological Science, 18(3), 233-239. https://doi.org/10.1111/j.1467-9280.2007.01882.x

Furr, R. M. (2011). Scale Construction Psychology Social and Personality and Psychometrics for. In Sage Publications.

Gámez, W., Chmielewski, M., Kotov, R., Ruggero, C., Suzuki, N., \& Watson, D. (2014). The grief Experiential Avoidance Questionnaire: Development and initial validation. Psychologieal Assessment, 26(1), 35-45. https://doi.org/10.1037/a0O34473

Gentes, E. L., \& Ruscio, A. M. (2011). A meta-analysis of the relation of intolerance of uncertainty to symptoms of generalized anxiety disorder, major depressive disorder, and obsessive-compulsive disorder. Clinical Psychology Review, 31(6), 923-933. https://doi.org/10.1016/j.cpr.2011.05.001

Goodman, J. K., Cryder, C. E., \& Cheema, A. (2013). Data Collection in a Flat World: The Strengths and Weaknesses of Mechanical Turk Samples. Journal of Behavioral Decision Making, 26(3), 213-224. https://doi.org/10.1002/bdm.1753

Goudarzi, S., Pliskin, R., Jost, J. T., \& Knowles, E. D. (2020). Economic system justification predicts muted emotional responses to inequality. Nature Communications, 11(1), 1-9. https://doi.org/10.1038/s41467-019-14193-z

Grant, B. F., Goldstein, R. B., Chou, S. P., Huang, B., Stinson, F. S., Dawson, D. A., Saha, T. D., Smith, S. M., Pulay, A. J., Pickering, R. P., Ruan, W. J., \& Compton, W. M. (2009). Sociodemographic and psychopathologic predictors of first incidence of DSM-IV substance use, mood and anxiety disorders: Results from the Wave 2 National Epidemiologic Survey on Alcohol and Related Conditions. Molecular Psychiatry, 14(11), 1051-1066. https://doi.org/10.1038/mp.2008.41

Greitemeyer, T., \& Sagioglou, C. (2016). Subjective socioeconomic status causes aggression: A test of the theory of social deprivation. Journal of Personality and Social Psychology, 111(2), 178-194. https://doi.org/10.1037/pspi0000058

Greitemeyer, T., \& Sagioglou, C. (2017). Increasing wealth inequality may increase interpersonal hostility: The relationship between personal relative deprivation and aggression. Journal of Social Psychology, 157(6), 766-776. https://doi.org/10.1080/00224545.2017.1288078

Haller, H., Cramer, H., Lauche, R., Gass, F., \& Dobos, G. J. (2014). The prevalence and burden of subthreshold generalized anxiety disorder: A systematic review. BMC Psychiatry, 14(1). https://doi.org/10.1186/1471-244X-14-128 
Hastings, O. P. (2019). Who feels it? Income inequality, relative deprivation, and financial satisfaction in U.S. states, 1973-2012. Research in Social Stratification and Mobility, 60(December 2018), 1-15. https://doi.org/10.1016/j.rssm.2019.01.004

Hayes, A. F. (2018). Introduction to Mediation, Moderation, and Conditional Process Analysis. Guilford Press.

Heimberg, Richard G., Turk, C. L., \& Mennin, D. S. (Eds.). (2004). Generalized anxiety disorder: Advances in research and practice. The Guilford Press. https://doi.org/10.1017/CBO9781107415324.004

Kessler, R. C., Aguilar-Gaxiola, S., Alonso, J., Chatterji, S., Lee, S., \& Ustün, T. B. (2009). The WHO World Mental Health (WMH) Surveys. Psychiatrie (Stuttgart, Germany), 6(1), 5-9. https://doi.org/10.1017/S1121189X00001421

Kessler, R. C., Berglund, P., Demler, O., Jin, R., Merikangas, K. R., \& Walters, E. E. (2005). Lifetime prevalence and age-of-onset distributions of DSM-IV disorders in the National Comorbidity Survey Replication. Arch Gen Psychiatry, 62(June), 593-602. https://doi.org/10.1001/archpsyc.62.6.593

Kessler, R. C., Gruber, M., Hettema, J. M., Hwang, I., Sampson, N., \& Yonkers, K. (2008). Comorbid major depression and generalized anxiety disorders in the National Comorbidity Survey follow-up. Psychological Medicine, 38(3), 365-374. https://doi.org/doi:10.1017/S0033291707002012

Kim, H.-Y. (2013). Statistical notes for clinical researchers: assessing normal distribution (2) using skewness and kurtosis. Restorative Dentistry \& Endodontics, 38(1), 52. https://doi.org/10.5395/rde.2013.38.1.52

Kim, H., Callan, M. J., Gheorghiu, A. I., \& Skylark, W. J. (2018). Social comparison processes in the experience of personal relative deprivation. Journal of Applied Social Psychology, 48(9), 519-532. https://doi.org/10.1111/jasp.12531

Koerner, N., \& Dugas, M. J. (2006). A cognitive model of generalized anxiety disorder: The role of intolerance of uncertainty. In G. C. L. Davey \& A. Wells (Eds.), Worry and its psychological disorders: Theory, assessment and treatment (pp. 201-216). John Wiley \& Sons Ltd.

Kondo, N., Sembajwe, G., Kawachi, I., van Dam, R. M., Subramanian, S. V., \& Yamagata, Z. (2009). Income inequality, mortality, and self rated health: meta-analysis of multilevel studies. BMJ, 339(7731). https://doi.org/10.1136/bmj.b4471

Kroenke, K., Spitzer, R. L., Williams, J. B. W., Monahan, P. O., \& Löwe, B. (2007). Anxiety disorders in primary care: Prevalence, impairment, comorbidity, and detection. Annals of Internal Medicine, 146(5), 317-325. https://doi.org/10.7326/0003-4819-146-5-20070306000004

Kroenke, K., Strine, T. W., Spitzer, R. L., Williams, J. B. W., Berry, J. T., \& Mokdad, A. H. (2009). The PHQ-8 as a measure of current depression in the general population. Journal of Affective Disorders, 114(1-3), 163-173. https://doi.org/10.1016/j.jad.2008.06.026

Ladouceur, R., Gosselin, P., \& Dugas, M. J. (2000). Experimental manipulation of intolerance of uncertainty: A study of a theoretical model of worry. Behaviour Research and Therapy, 38(9), 933-941. https://doi.org/10.1016/S0005-7967(99)00133-3

Lahey, B. B. (2009). Public Health Significance of Neuroticism. American Psychologist, 64(4), 241-256. https://doi.org/10.1037/a0015309

Laugesen, N., Dugas, M. J., \& Bukowski, W. M. (2003). Understanding adolescent worry: The application of a cognitive model. Journal of Abnormal Child Psychology, 31(1), 55-64. 
https://doi.org/10.1023/A:1021721332181

Lewis, E. J., Yoon, K. L., \& Joormann, J. (2017). Emotion regulation and biological stress responding: associations with worry, rumination, and reappraisal. Cognition and Emotion, 32(7), 1487-1498. https://doi.org/10.1080/02699931.2017.1310088

Löwe, B., Decker, O., Müller, S., Brähler, E., Schellberg, D., Herzog, W., Herzberg, P. Y., Care, S. M., Mar, N., Lowe, B., Decker, O., Miiller, S., \& Brdhler, E. (2017). Validation and standardization of the Generalized Anxi Disorder Screener (GAD-7) in the general population. Medical Care, 46(3), 266-274.

https://doi.org/10.1097/MLR.0b013e318160d093

Luthar, S. S. (2003). The Culture of Affluence: Psychological Costs of Material Wealth. Child Development, 74(6), 1581-1593. https://doi.org/10.1046/j.1467-8624.2003.00625.x

Mennin, D. S. (2005). Emotion and the Acceptance-Based Approaches to the Anxiety Disorders. In S. M. Orsillo \& L. Roemer (Eds.), Series in anxiety and related disorders. Acceptance and mindfulness based approaches to anxiety: Conceptualization and treatment (pp. 3768). Springer Science + Business Media. https://doi.org/10.1007/0-387-25989-9_2

Mennin, D. S., Heimberg, R. G., Turk, C. L., \& Fresco, D. M. (2002). Applying an emotion regulation framework to integrative approaches to generalized anxiety disorder. Clinical Psychology: Science and Practice, 9(1), 85-90. https://doi.org/10.1093/clipsy/9.1.85

Mishra, S., \& Carleton, N. R. (2015). Subjective relative deprivation is associated with poorer physical and mental health. Social Science \& Medicine, 147, 144-149. https://doi.org/10.1016/j.socscimed.2015.10.030

Mishra, S., \& Meadows, T. J. S. (2018). Does stress mediate the association between personal relative deprivation and gambling? Stress and Health, 34(2), 331-337. https://doi.org/10.1002/smi.2789

Mishra, S., \& Novakowski, D. (2016). Personal relative deprivation and risk: An examination of individual differences in personality, attitudes, and behavioral outcomes. Personality and Individual Differences, 90, 22-26. https://doi.org/10.1016/j.paid.2015.10.031

Moffitt, T. E., Caspi, A., Harrington, H., Milne, B. J., Melchior, M., Goldberg, D., \& Poulton, R. (2007). Generalized anxiety disorder and depression: Childhood risk factors in a birth cohort followed to age 32. Psychological Medicine, 37(3), 441-452. https://doi.org/10.1017/S0033291706009640

Moffitt, T. E., Harrington, H., Caspi, A., Kim-Cohen, J., Goldberg, D., Gregory, A. M., \& Poulton, R. (2007). Depression and Generalized Anxiety Disorder. Archives of General Psychiatry, 64(6), 651. https://doi.org/10.1001/archpsyc.64.6.651

Mosca, O., Lauriola, M., \& Carleton, R. N. (2016). Intolerance of uncertainty: A temporary experimental induction procedure. PLoS ONE, 11(6), 1-15. https://doi.org/10.1371/journal.pone.0155130

Muris, P. (2002). Relationships between self-efficacy and symptoms of anxiety disorders and depression in a normal adolescent sample. Personality and Individual Differences, 32(2), 337-348. https://doi.org/10.1016/S0191-8869(01)00027-7

Nadler, J., Day, M. V, Beshai, S., \& Mishra, S. (2020). The relative deprivation trap: How feeling deprived relates to symptoms of generalized anxiety disorder. Journal of Social and Clinical Psychology, 39(10), 897-922. https://doi.org/10.1521/jscp.2020.39.10.897

Nasiri, F., Mashhadi, A., Bigdeli, I., \& Chamanabad, A. G. (2019). How to Differentiate Generalized Anxiety Disorder from Worry: The Role of Cognitive Strategies. Journal of Rational - Emotive and Cognitive - Behavior Therapy, 38(1), 44-55. 
https://doi.org/10.1007/s 10942-019-00323-5

Norr, A. M., Oglesby, M. E., Capron, D. W., Raines, A. M., Korte, K. J., \& Schmidt, N. B. (2013). Evaluating the unique contribution of intolerance relative to other cognitive vulnerability factors in of uncertainty anxiety psychopathology. Journal of Affective Disorders, 151(1), 136-142. https://doi.org/10.1016/j.jad.2013.05.063

Operario, D., Adler, N. E., \& Williams, D. R. (2004). Subjective social status: Reliability and predictive utility for global health. Psychology and Health, 19(2), 237-246. https://doi.org/10.1080/08870440310001638098

Osborne, D., Sibley, C. G., \& Sengupta, N. K. (2015). Income and neighbourhood-level inequality predict self-esteem and ethnic identity centrality through individual- and groupbased relative deprivation: A multilevel path analysis. European Journal of Social Psychology, 45, 368-377. https://doi.org/10.1002/ejsp.2087

Osborne, D., Smith, H. J., \& Huo, Y. J. (2012). More than a feeling: Discrete emotions mediate the relationship between relative deprivation and reactions to workplace furloughs. Personality and Social Psychology Bulletin, 38(5), 628-641. https://doi.org/10.1177/0146167211432766

Pearson, C., Janz, T., \& Ali, J. (2013). Mental and substance use disorders in Canada. Statistics Canada, 82, 1-8. https://doi.org/82-624-X

Peer, E., Brandimarte, L., Samat, S., \& Acquisti, A. (2017). Beyond the Turk: Alternative platforms for crowdsourcing behavioral research. Journal of Experimental Social Psychology, 70, 153-163. https://doi.org/10.1016/j.jesp.2017.01.006

Penney, A. M., Mazmanian, D., \& Rudanycz, C. (2013). Comparing positive and negative beliefs about worry in predicting generalized anxiety disorder symptoms. Canadian Journal of Behavioural Science, 45(1), 34-41. https://doi.org/10.1037/a0027623

Pettigrew, T. F. (2015). Samuel Stouffer and Relative Deprivation. Social Psychology Quarterly, 78(1), 7-24. https://doi.org/10.1177/0190272514566793

Pettigrew, T. F. (2016). In pursuit of three theories: Authoritarianism, relative deprivation, and intergroup Contact. Annual Review of Psychology, 67(1), 1-21. https://doi.org/10.1146/annurev-psych-122414-033327

Pickett, K. E., James, O. W., \& Wilkinson, R. G. (2006). Income inequality and the prevalence of mental illness: A preliminary international analysis. Journal of Epidemiology and Community Health, 60(7), 646-647. https://doi.org/10.1136/jech.2006.046631

Pickett, K. E., \& Wilkinson, R. G. (2010). Inequality: an underacknowledged source of mental illness and distress. The British Journal of Psychiatry, 197, 426-428. https://doi.org/10.1192/bjp.bp.109.072066

Pickett, K. E., \& Wilkinson, R. G. (2015). Income inequality and health: A causal review. Social Science \& Medicine, 128, 316-326. https://doi.org/10.1016/j.socscimed.2014.12.031

Preacher, K. J., \& Hayes, A. F. (2008). Asymptotic and resampling strategies for assessing and comparing indirect effects in multiple mediator models. Behavior Research Methods, 40(3), 879-891. https://doi.org/10.3758/BRM.40.3.879

Rivenbark, J., Arseneault, L., Caspi, A., Danese, A., Fisher, H. L., Moffitt, T. E., Rasmussen, L. J. H., Russell, M. A., \& Odgers, C. L. (2020). Adolescents' perceptions of family social status correlate with health and life chances: A twin difference longitudinal cohort study. Proceedings of the National Academy of Sciences, 1-6. https://doi.org/10.1073/pnas.1820845116

Roemer, L., \& Orsillo, S. M. (2005). An Acceptance-Based Behaviour Therapy for Generalized 
Anxiety Disorder. In S. M. Orsillo \& L. Roemer (Eds.), Acceptance and Mindfulness-Based Approaches to Anxiety: Conceptualization and Treatment. Springer.

Runciman, W. G., \& Runciman, B. (1966). Relative deprivation and social justice: A study of attitudes to social inequality in twentieth-century England. (Vol. 13). University of California Press.

Ruscio, A. M., \& Borkovec, T. D. (2004). Experience and appraisal of worry among high worriers with and without generalized anxiety disorder. Behaviour Research and Therapy, 42(12), 1469-1482. https://doi.org/10.1016/j.brat.2003.10.007

Ruscio, A. M., Hallion, L. S., Lim, C. C. W., Aguilar-Gaxiola, S., Al-Hamzawi, A., Alonso, J., Andrade, L. H., Borges, G., Bromet, E. J., Bunting, B., De Almeida, J. M. C.,

Demyttenaere, K., Florescu, S., De Girolamo, G., Gureje, O., Haro, J. M., He, Y., Hinkov, H., Hu, C., ... Scott, K. M. (2017). Cross-sectional comparison of the epidemiology of DSM-5 generalized anxiety disorder across the globe. JAMA Psychiatry, 74(5), 465-475. https://doi.org/10.1001/jamapsychiatry.2017.0056

Ruscio, A. M., \& Khazanov, G. K. (2017). Anxiety and Depression. In R. J. DeRubeis \& D. R. Strunk (Eds.), The Oxford Handbook of Mood Disorders (pp. 313-324). Oxford University Press.

Scherbaum, C. A., Cohen-Charash, Y., \& Kern, M. J. (2006). Measuring general self-efficacy: A comparison of three measures using item response theory. Educational and Psychological Measurement, 66(6), 1047-1063. https://doi.org/10.1177/0013164406288171

Scott, K. M., Al-Hamzawi, A. O., Andrade, L. H., Borges, G., Caldas-de-Almeida, J. M., Fiestas, F., Gureje, O., Hu, C., Karam, E. G., Kawakami, N., Lee, S., Levinson, D., Lim, C. C. W., Navarro-Mateu, F., Okoliyski, M., Posada-Villa, J., Torres, Y., Williams, D. R., Zakhozha, V., \& Kessler, R. C. (2014). Associations between subjective social status and DSM-IV mental disorders. JAMA Psychiatry, 71(12), 1400-1408. https://doi.org/10.1001/jamapsychiatry.2014.1337

Sinclair, S. J., Blais, M. A., Gansler, D. A., Sandberg, E., Bistis, K., \& LoCicero, A. (2010). Psychometric properties of the Rosenberg Self-Esteem Scale: Overall and across demographic groups living within the United States. Evaluation and the Health Professions, 33(1), 56-80. https://doi.org/10.1177/0163278709356187

Singh-Manoux, A., Adler, N. E., \& Marmot, M. G. (2003). Subjective social status: Its determinants and its association with measures of ill-health in the Whitehall II study. Social Science \& Medicine, 56(6), 1321-1333. https://doi.org/10.1016/S0277-9536(02)00131-4

Smith, H. J., \& Huo, Y. J. (2014). Relative deprivation: How subjective experiences of inequality influence social behaviour and health. Behavioral and Brain Sciences, 1(1), 231238. https://doi.org/10.1177/2372732214550165

Smith, H. J., \& Ortiz, D. J. (2002). Is it just me?: The different consequences of personal and gorup deprivation. In I. Walker \& H. J. Smith (Eds.), Relative deprivation: Specification, development and integration (pp. 91-115). Cambridge University Press.

Smith, H. J., \& Pettigrew, T. F. (2015). Advances in relative deprivation theory and research. Social Justice Research, 28(1), 1-6. https://doi.org/10.1007/s11211-014-0231-5

Smith, H. J., Pettigrew, T. F., Pippin, G. M., \& Bialosiewicz, S. (2012). Relative deprivation: A theoretical and meta-analytic review. Personality and Social Psychology Review, 16(3), 203-232. https://doi.org/10.1177/1088868311430825

Smith, H. J., Ryan, D. A., Jaurique, A., \& Duffau, E. (2020). Personal relative deprivation and mental health among university students: cross-sectional and longitudinal evidence. 
Analyses of Social Issues and Public Policy.

https://doi.org/https://doi.org/10.1111/asap.12201

Smith, H. J., Ryan, D. A., Jaurique, A., Pettigrew, T. F., Jetten, J., Ariyanto, A., Autin, F., Ayub, N., Badea, C., Besta, T., Butera, F., Costa-Lopes, R., Cui, L., Fantini, C., Finchilescu, G., Gaertner, L., Gollwitzer, M., Gómez, Á., González, R., ... Wohl, M. (2018). Cultural values moderate the impact of relative deprivation. Journal of Cross-Cultural Psychology, 49(8), 1183-1218. https://doi.org/10.1177/0022022118784213

Sowislo, J. F., \& Orth, U. (2013). Does low self-esteem predict depression and anxiety? A metaanalysis of longitudinal studies. Psychological Bulletin, 139(1), 213-240. https://doi.org/10.1037/a0028931

Spada, M. M., Mohiyeddini, C., \& Wells, A. (2008). Measuring metacognitions associated with emotional distress: Factor structure and predictive validity of the metacognitions questionnaire 30. Personality and Individual Differences, 45(3), 238-242. https://doi.org/10.1016/j.paid.2008.04.005

Spitzer, R. L., Kroenke, K., Williams, J. B. W., \& Löwe, B. (2006). A brief measure for assessing generalized anxiety disorder: The GAD-7. Archives of Internal Medicine, 166(10), 1092-1097. https://doi.org/10.1001/archinte.166.10.1092

Stanley, M. A., Novy, D. M., Hopko, D. R., Beck, J. G., Averill, P. M., \& Swann, A. C. (2002). Measures of self-efficacy and optimism in older adults with generalized anxiety. Assessment, 9(1), 70-81. https://doi.org/10.1177/1073191102009001009

Stouffer, S. A., Suchman, E. A., DeVinney, L. C., Star, S. A., \& Williams Jr., R. M. (1949). The American soldier: Adjustment during army life. Princeton University Press.

Sweeney, P. D., McFarlin, D. B., \& Inderrieden, E. J. (1990). Using relative deprivation theory to explain satisfaction with income and pay level: A multistudy examination. Academy of Management Journal, 33(2), 423-436. https://doi.org/10.2307/256332

Tougas, F., \& Beaton, A. M. (2002). Personal and group relative deprivation: Connecting the "I" to the "We." In I. Walker \& H. J. Smith (Eds.), Relative deprivation: Specification, development and integration (pp. 119-135). Cambridge University Press.

Valentiner, D. P., Fergus, T. A., Behar, E., \& Conybeare, D. J. (2014). Anxiety Disorders. In D. C. Beidel, C. B. Frueh, \& M. Hersen (Eds.), Adult psychopathology and diagnosis (7th ed., pp. 299-353). John Wiley \& Sons, Inc.

Wahlbeck, K., Cresswell-Smith, J., Haaramo, P., \& Parkkonen, J. (2017). Interventions to mitigate the effects of poverty and inequality on mental health. Social Psychiatry and Psychiatric Epidemiology, 52(5), 505-514. https://doi.org/10.1007/s00127-017-1370-4

Walker, I. (1999). Effects of personal and group relative deprivation on personal and collective self-esteem. Group Processes and Intergroup Relations, 2(4), 365-380. https://doi.org/10.1177/1368430299024004

Walker, I., \& Pettigrew, T. F. (1984). Relative deprivation theory: An overview and conceptual critique. British Journal of Social Psychology, 23(4), 301-310. https://doi.org/10.1111/j.2044-8309.1984.tb00645.x

Walker, I., \& Smith, H. J. (2002). Fifty years of relative deprivation research. In W. Iain \& H. J. Smith (Eds.), Relative deprivation: Specification, development and integration (pp. 1-9). Cambridge University Press.

Watkins, E. (2004). Adaptive and maladaptive ruminative self-focus during emotional processing. Behaviour Research and Therapy, 42, 1037-1052. https://doi.org/10.1016/j.brat.2004.01.009 
Watkins, E. R. (2008). Constructive and Unconstructive Repetitive Thought. Psychological Bulletin, 134(2), 163-206. https://doi.org/10.1037/0033-2909.134.2.163

Watterson, R. A., Williams, J. V. A., Lavorato, D. H., \& Patten, S. B. (2017). Descriptive Epidemiology of Generalized Anxiety Disorder in Canada. Canadian Journal of Psychiatry, 62(1), 24-29. https://doi.org/10.1177/0706743716645304

Weich, S., Lewis, G., \& Jenkins, S. P. (2001). Income inequality and the prevalence of common mental disorders in Britain. The British Journal of Psychiatry, 178(3), 222-227. https://doi.org/10.1192/BJP.178.3.222

Wells, A. (2004). A Cognitive Model of GAD: Metacognitions and Pathological Worry. In Richard G. Heimberg, C. L. Turk, \& D. S. Mennin (Eds.), Generalized anxiety disorder: Advances in research and practice (pp. 164-186).

Wells, A. (2005). The metacognitive model of GAD: Assessment of meta-worry and relationship with DSM-IV generalized anxiety disorder. Cognitive Therapy and Research, 29(1), 107121. https://doi.org/10.1007/s10608-005-1652-0

Wells, A., \& Cartwright-Hatton, S. (2004). A short form of the metacognitions questionnaire: Properties of the MCQ-30. Behaviour Research and Therapy, 42(4), 385-396. https://doi.org/10.1016/S0005-7967(03)00147-5

WHO International Consortium in Psychiatric Epidemiology. (2000). Cross-national comparisons of the prevalences and correlates of mental disorders. Bulletin of the World Health Organization, 78(4), 413-426. https://doi.org/10.1590/S0042-96862000000400003

Wilkinson, R. G., \& Pickett, K. E. (2006). Income inequality and population health: A review and explanation of the evidence. Social Science \& Medicine, 62, 1768-1784. https://doi.org/10.1016/j.socscimed.2005.08.036

Wilkinson, R. G., \& Pickett, K. E. (2010). The Spirit Level: Why more equal socieities almost always do better. Bloomsbury Press.

Wittchen, H.-U. (2002). Generalized anxiety disorder: Prevalence, burden, and cost to society. Depression and Anxiety, 16(4), 162-171. https://doi.org/10.1002/da.10065

Yook, K., Kim, K. H., Suh, S. Y., \& Lee, K. S. (2010). Intolerance of uncertainty, worry, and rumination in major depressive disorder and generalized anxiety disorder. Journal of Anxiety Disorders, 24(6), 623-628. https://doi.org/10.1016/j.janxdis.2010.04.003

Zhao, X., Lynch, J. G., \& Chen, Q. (2010). Reconsidering Baron and Kenny: Myths and Truths about Mediation Analysis. Journal of Consumer Research, 37(2), 197-206. https://doi.org/10.1086/651257 


\section{Appendices}

Appendix A: Study 1 Materials

Personal Relative Deprivation

Personal Relative Deprivation Scale - Revised (PRDS-R)

Please indicate to what extent do you agree or disagree with each of the following. (1=Strongly disagree, $7=$ Strongly agree)

1. I feel deprived when I think about what I have compared to what other people like me have.

2. I feel privileged compared to other people like me.*

3. I feel resentful when I see how prosperous other people like me seem to be.

4. When I compare what I have with what others like me have, I realize that I am quite well off.*

5. I feel dissatisfied with what I have compared to what other people like me have.

* Indicates reverse-scored item.

Intolerance of Uncertainty

Intolerance of Uncertainty Scale - 12 (IUS-12)

You will find below a series of statements which describe how people may react to the uncertainties of life. Please use the scale below to describe to what extent each item is characteristic of you. $(1=$ Not at all characteristic of me, $5=$ Entirely characteristic of me $)$

1. Unforeseen events upset me greatly.

2. It frustrates me not having all the information I need.

3. Uncertainty keeps me from living a full life.

4. One should always look ahead so as to avoid surprises.

5. A small unforeseen event can spoil everything, even with the best of planning.

6. When it's time to act, uncertainty paralyses me.

7. When I am uncertain I can't function very well.

8. I always want to know what the future has in store for me.

9. I can't stand being taken by surprise.

10. The smallest doubt can stop me from acting.

11. I should be able to organize everything in advance.

12. I must get away from all uncertain situations.

\section{Metacognitions about Worry}

Metacognitions Questionnaire - 30 (MCQ-30)

(2 of the 5 scales of the MCQ-30 were used)

This questionnaire is concerned with beliefs people have about their thinking. Listed below are a number of beliefs that people have expressed. Please read each item and indicate how much you generally agree with it. Please respond to all of the items, there are no right or wrong answers. ( 1 = Do not agree, $4=$ Agree very much). 
Positive Beliefs

1. Worrying helps me to get things sorted out in my mind.

2. Worrying helps me cope.

3. I need to worry in order to work well.

4. Worrying helps me to solve problems.

5. I need to worry in order to remain organized.

6. Worrying helps me to avoid problems in the future.

Negative Beliefs

7. My worrying thoughts persist, no matter how I try to stop them.

8. When I start worrying I cannot stop.

9. I could make myself sick with worrying.

10. I cannot ignore my worrying thoughts.

11. My worrying could make me go mad.

12. My worrying is dangerous for me.

\section{Generalized Anxiety Disorder Symptoms}

GAD-7

Please consider how you have been feeling in the last 2 weeks.

How often have you been feeling the following? $(0=$ not at all, $3=$ nearly every day $)$

1. Feeling nervous, anxious or on edge

2. Not being able to stop or control worrying

3. Worrying too much about different things

4. Trouble relaxing

5. Being so restless that it is hard to sit still

6. Becoming easily annoyed or irritable

7. Feeling afraid as if something awful might happen

\section{Self-Efficacy}

New General Self-Efficacy Scale (NGSE)

Please indicate to what extent you agree with each of the following statements. $(1=$ Strongly Disagree, 7 = Strongly Agree)

1. I will be able to achieve most of the goals that I have set for myself.

2. When facing difficult tasks, I am certain that I will accomplish them.

3. In general, I think that I can obtain outcomes that are important to me.

4. I believe I can succeed at most any endeavor to which I set my mind.

5. I will be able to successfully overcome many challenges.

6. I am confident that I can perform effectively on many different tasks. 
7. Compared to other people, I can do most tasks very well.

8. Even when things are tough, I can perform quite well. 
Study 1 Assumption of Normality

We evaluated the skewness and kurtosis of key Study 1 variables to check assumptions of normality. As this sample has a relatively large sample size $(n>300)$, deviations from normalcy are considered present when the absolute value of the skewness and kurtosis are greater than 2 (Fagerland, 2012; H.-Y. Kim, 2013). None of the variables show such deviation.

Table B1: Skewness and Kurtosis for key study 1 variables

\begin{tabular}{lcccccc}
\hline & Skewness & $\begin{array}{c}\text { Std. Error } \\
\text { Skew }\end{array}$ & $\begin{array}{c}\text { Skew } \\
\text { Z-score }\end{array}$ & Kurtosis & $\begin{array}{c}\text { Std. Error } \\
\text { Kurt }\end{array}$ & $\begin{array}{c}\text { Kurt Z- } \\
\text { Score }\end{array}$ \\
\hline PRD & 0.170 & 0.101 & 1.683 & -0.149 & 0.201 & -0.741 \\
IU & 0.152 & 0.101 & 1.505 & -0.557 & 0.201 & -2.771 \\
PBW & 0.735 & 0.101 & 7.277 & -0.241 & 0.201 & -1.199 \\
NBW & 0.527 & 0.101 & 5.218 & -0.616 & 0.201 & -3.065 \\
GAD & 0.880 & 0.101 & 8.713 & 0.103 & 0.201 & 0.512 \\
SF & -0.741 & 0.101 & -7.337 & 1.112 & 0.201 & 5.532 \\
\hline
\end{tabular}

Study 1 Assumption of Non-Multicollinearity

In order to verify that the constructs should be considered independent predictors we examined multicollinearity statistics. While there are various guidelines for interpreting multicollinearity, a Variance Inflation Factor (VIF) in excess of 5 may be problematic. None of the VIFs for the predictor or mediating variables in the Study 1 analysis including PRD, IU, PBW, NBW, and GAD show reason for any strong concern about multicollinearity. Additionally, the high reliability of our measures (e.g., all alphas $>.83$ ), and the large proportion of variance explained by these measures further support treating the constructs as independent predictors.

Table B2: Multicollinearity coefficients for generalized anxiety disorder symptoms, and proposed mediators for Study 1

\begin{tabular}{ll}
\hline & VIF \\
\hline PRD & 1.325 \\
IU & 2.180 \\
PBW & 1.120 \\
NBW & 1.874 \\
\hline
\end{tabular}

Total $\mathrm{R}^{2}=.591$ 


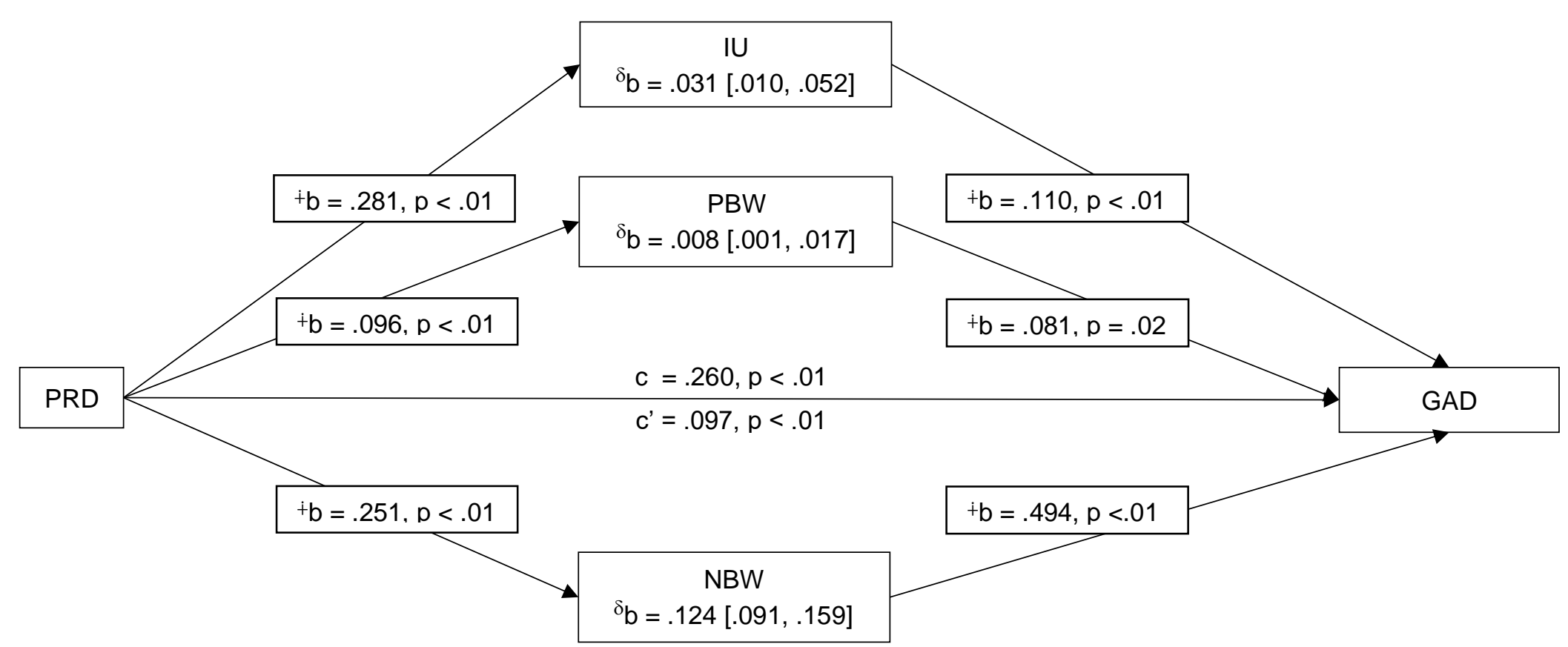

Figure C1: 3-mediator model with demographic covariates (age, sex, level of education, household income), Study 1.

Note: PRD = personal relative deprivation, IU = intolerance of uncertainty PBW = positive beliefs about worry, NBW=negative beliefs about worry, GAD = generalized anxiety disorder symptom; $\delta=$ indirect effect; $\dot{+}=$ direct effect; $c=$ total effect of PRD on GAD; $c^{\prime}=$ direct effect of PRD on GAD 
Appendix D: Study 2 Materials

The scales use to measure PRD and GAD symptoms were the exact same as those used in Study 1. Changes in phrasing or scale for measures of $I U, P B W$, and $N B W$ are indicated below in bold.

\section{Intolerance of Uncertainty}

Intolerance of Uncertainty Scale - 12 (IUS-12)

You will find below a series of statements which describe how people may react to the uncertainties of life. Please use the scale below to describe to what extent each item is characteristic of you. $(1=$ Strongly Disagree, $7=$ Strongly Agree $)$

1. Unforeseen events upset me greatly.

2. It frustrates me not having all the information I need.

3. Uncertainty keeps me from living a full life.

4. One should always look ahead so as to avoid surprises.

5. A small unforeseen event can spoil everything, even with the best of planning.

6. When it's time to act, uncertainty paralyses me.

7. When I am uncertain I can't function very well.

8. I always want to know what the future has in store for me.

9. I can't stand being taken by surprise.

10. The smallest doubt can stop me from acting.

11. I should be able to organize everything in advance.

12. I must get away from all uncertain situations.

Metacognitions about Worry

Metacognitions Questionnaire - 30 (MCQ-30)

(2 of the 5 scales of the $M C Q-30$ were used)

This questionnaire is concerned with beliefs people have about their thinking. Listed below are a number of beliefs that people have expressed. Please read each item and indicate how much you generally agree with it. Please respond to all of the items, there are no right or wrong answers. ( 1 = Strongly Disagree, 7 = Strongly Agree $)$

Positive Beliefs

1. Worrying helps me to get things sorted out in my mind.

2. Worrying helps me cope.

3. I need to worry in order to work well.

4. Worrying helps me to solve problems.

5. I need to worry in order to remain organized.

6. Worrying helps me to avoid problems in the future. 
Negative Beliefs

1. My worrying thoughts persist, no matter how I try to stop them.

2. When I start worrying I cannot stop.

3. I could make myself sick with worrying.

4. I cannot ignore my worrying thoughts.

5. My worrying could make me go mad.

6. My worrying is dangerous for me.

Experiential Avoidance

Brief Experiential Avoidance Questionnaire (BEAQ)

Please indicate the extent to which you agree or disagree with each of the following statements. (1 = Strongly Disagree, 7 = Strongly Agree $)$

*Indicates reverse-scored item

1. The key to a good life is never feeling any pain.

2. I'm quick to leave any situation that makes me feel uneasy

3. When unpleasant memories come to me, I try to put them out of my mind.

4. I feel disconnected from my emotions.

5. I won't do something unless I absolutely have to.

6. Fear or anxiety won't stop me from doing something important.*

7. I would give up a lot not to feel bad.

8. I rarely do something if there is a chance it will upset me.

9. It's hard for me to know what I'm feeling.

10. I try to put off unpleasant tasks for as long as possible.

11. I go out of my way to avoid uncomfortable situations.

12. One of my big goals is to be free from painful emotions.

13. I work hard to keep out upsetting feelings.

14. If I have any doubts about doing something, I just won't do it

15. Pain always leads to suffering.

\section{Self-Esteem}

Rosenberg Self-Esteem Scale

Below is a list of statements dealing with your general feelings about yourself.

Please indicate your agreement with the following statements. ( $1=$ Strongly disagree, $7=$ Strongly agree)

*Indicates reverse-scored item

1. On the whole, I am satisfied with myself.

2. At times, I think I am no good at all.*

3. I feel that I have a number of good qualities.

4. I am able to do things as well as most other people.

5. I feel I do not have much to be proud of.*

6. I certainly feel useless at times. *

7. I feel that I'm a person of worth, at least on an equal plane with others. 
8. I wish I could have more respect for myself. *

9. All in all, I am inclined to feel that I am a failure. *

10. I take a positive attitude toward myself.

\section{Subjective SES}

Think of this ladder to the right as representing where people stand in America.

At the top of the ladder are the people who are the best off - those who have the most money, the most education, and the most respected jobs. At the bottom are the people who are the worst off - who have the least money, least education, and the least respected jobs or no job.

The higher up you are on this ladder, the closer you are to the people at the very top; the lower you are, the closer you are to the people at the very bottom.

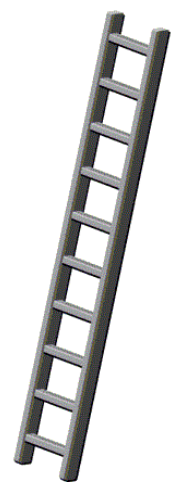

If 10 is the top of the ladder and 1 is the bottom, where would you place yourself on this ladder? 


\section{Appendix E: Study 1 Assumption Checks}

Study 2 Assumption of Normality

We evaluated the skewness and kurtosis of key Study 2 variables to check assumptions of normality. As this sample had a medium-to-large sample size $(n=301)$, deviations from normalcy are considered present when the $\mathrm{z}$-score of the skewness or kurtosis value is greater than 3.29 (Kim, 2013). The only variables that meet these criteria are our symptom measures, the GAD-7 and PHQ-8, as they appear to be unimodal and positively skewed. However, non-normal distributions are extremely common in health and social-science based research (Bono et al., 2017). Additionally, bootstrap mediation analysis does not require an assumption of normality for the indirect pathway, our primary outcome variable, and is in fact most useful when the sample is representative of the population (Hayes, 2018). Moreover, examining correlations between skewed and non-skewed data, as would be the case when comparing GAD to our other non-symptom variables, is more likely to reduce the correlations observed, rather than inflate them (Furr, 2011). For these reasons we elected not to transform our data for analyses.

Table E1: Skewness and Kurtosis for key Study 2 variables

\begin{tabular}{lcccccc}
\hline & Skewness & $\begin{array}{c}\text { Std. Error } \\
\text { of Skew }\end{array}$ & $\begin{array}{c}\text { Skew Z- } \\
\text { score }\end{array}$ & Kurtosis & $\begin{array}{c}\text { Std. Error } \\
\text { of Kurt }\end{array}$ & $\begin{array}{c}\text { Kurt Z- } \\
\text { Score }\end{array}$ \\
\hline PRD & 0.195 & 0.140 & 1.393 & -0.445 & 0.280 & 1.393 \\
PBW & 0.205 & 0.140 & 1.464 & -0.779 & 0.280 & 1.464 \\
NBW & -0.070 & 0.140 & -0.500 & -1.038 & 0.280 & -0.500 \\
IU & 0.054 & 0.140 & 0.386 & -0.488 & 0.280 & 0.386 \\
EA & -0.013 & 0.140 & -0.093 & -0.023 & 0.280 & -0.093 \\
GAD & 0.723 & 0.140 & 5.164 & -0.326 & 0.280 & 5.164 \\
SE & -0.426 & 0.141 & -3.021 & -0.509 & 0.281 & -3.021 \\
PHQ & 0.778 & 0.140 & 5.557 & -0.322 & 0.280 & 5.557 \\
\hline
\end{tabular}

Study 2 Assumption of non-multicollinearity

As with Study 1 (above) we examined multicollinearity statistics to ensure that the constructs should be considered independent predictors. None of the VIFs for the predictor or mediating variables in the Study 2 analysis including PRD, IU, PBW, NBW, EA and GAD show reason for any strong concern about multicollinearity.

Table E2: Multicollinearity Coefficients for generalized anxiety disorder symptoms, PRD, and proposed mediators Study 2

\begin{tabular}{ll}
\hline & VIF \\
\hline PRD & 1.236 \\
IU & 2.180 \\
PBW & 1.120 \\
NBW & 1.874 \\
EA & 2.203 \\
\hline
\end{tabular}

Total $\mathrm{R}^{2}=.606$ 


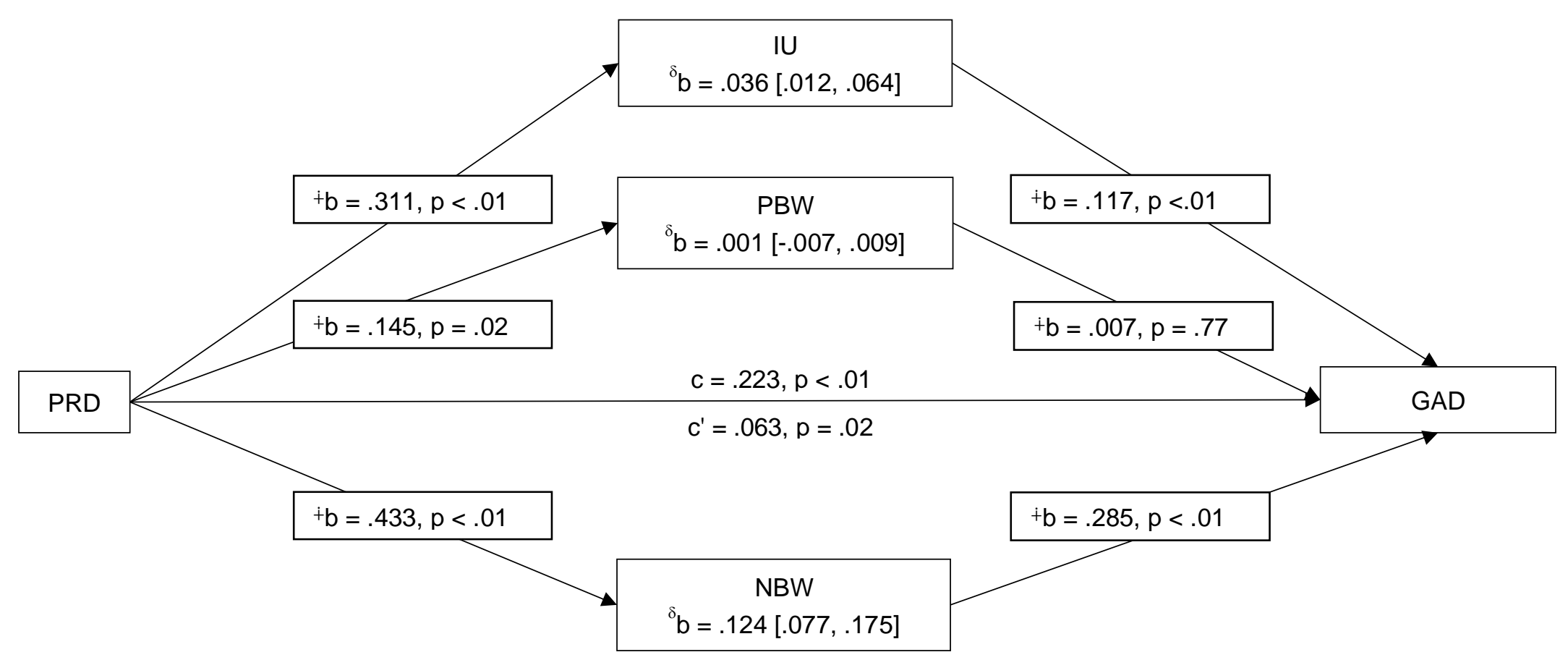

Figure F1: 3-mediator model with demographic covariates (age, sex, level of education, household income), Study 2 Note: $\mathrm{PRD}=$ personal relative deprivation, IU = intolerance of uncertainty PBW = positive beliefs about worry, NBW=negative beliefs about worry, $\mathrm{GAD}=$ generalized anxiety disorder symptom; $\delta=$ indirect effect; $\dot{+}=$ direct effect; $\mathrm{c}=$ total effect of PRD on $\mathrm{GAD} ; \mathrm{c}^{\prime}=$ direct effect of PRD on GAD 


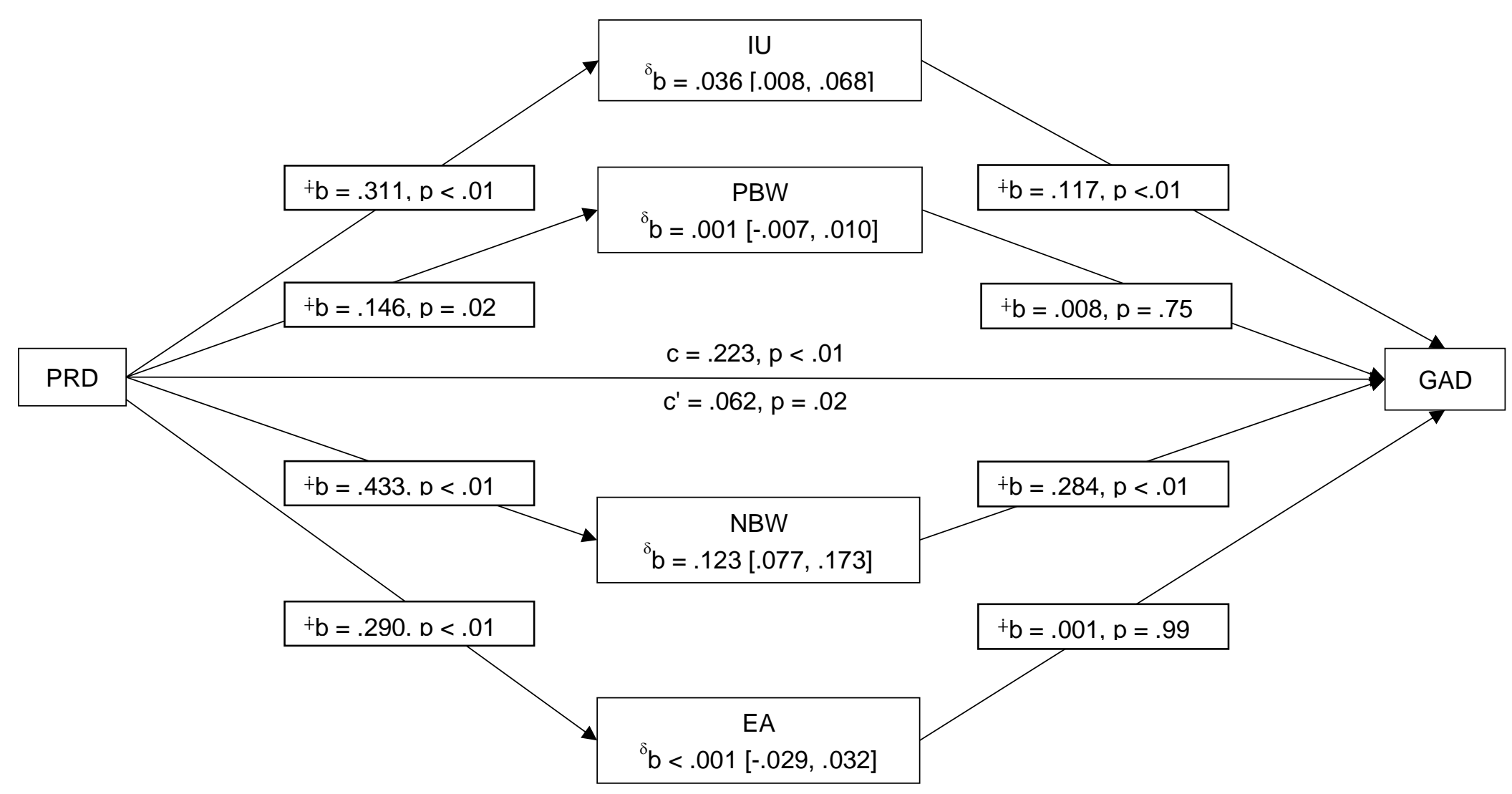

Figure F2: 4-Mediator Model including demographic covariates (age, sex, level of education, household income, ethnicity), Study 2 Note: PRD = personal relative deprivation, IU = intolerance of uncertainty PBW = positive beliefs about worry, NBW=negative beliefs about worry, GAD = generalized anxiety disorder symptom; $\delta=$ indirect effect; $\dot{+}=$ direct effect; $\mathrm{c}=$ total effect of PRD on GAD; $c^{\prime}=$ direct effect of PRD on GAD 


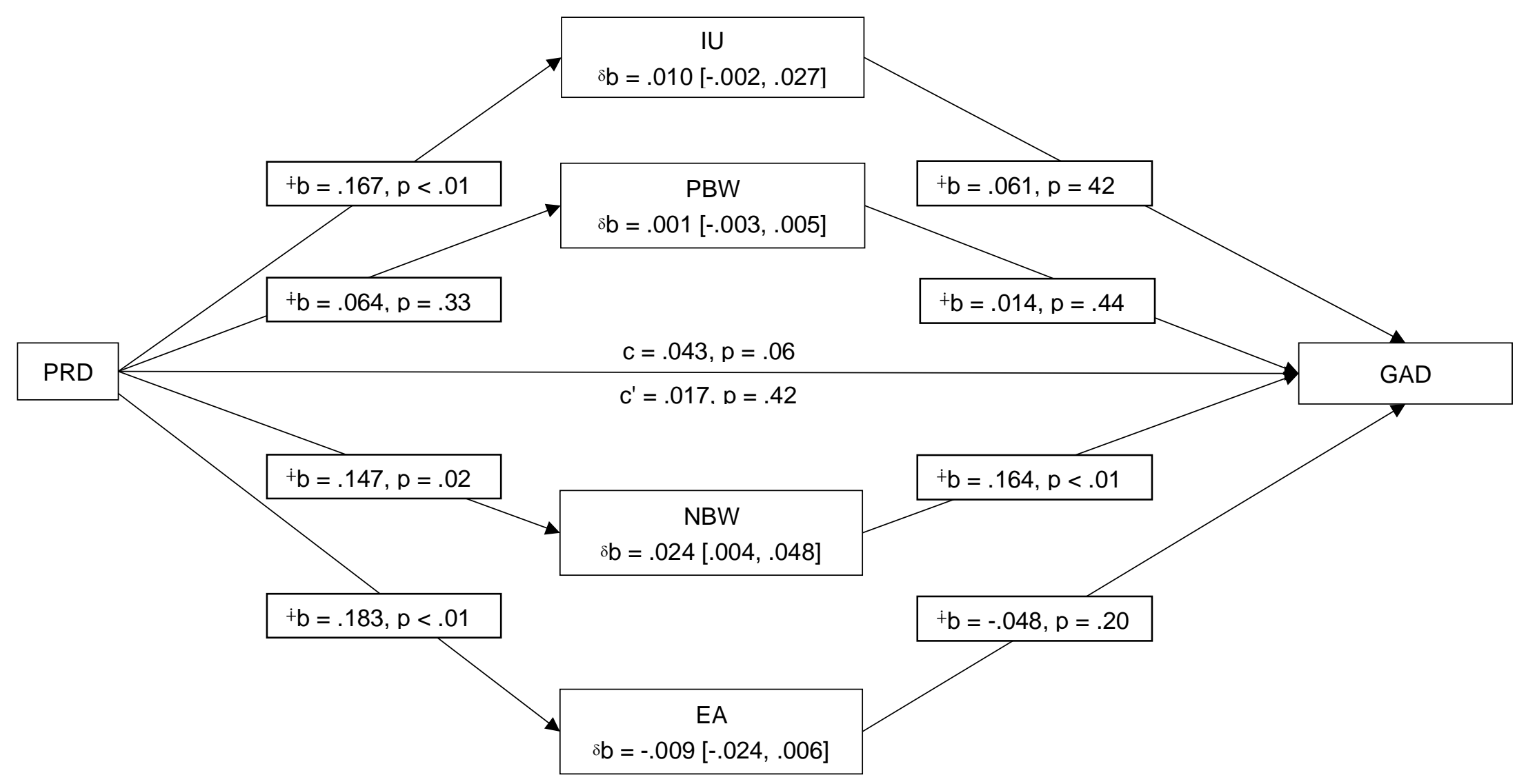

Figure F3: 4-Mediator Model including depression as a covariate, Study 2

Note: PRD = personal relative deprivation, IU = intolerance of uncertainty PBW = positive beliefs about worry, NBW=negative beliefs about worry, GAD = generalized anxiety disorder symptom; $\delta=$ indirect effect; $\dot{+}=$ direct effect; $\mathrm{c}=$ total effect of PRD on GAD; $c^{\prime}=$ direct effect of PRD on GAD 